\title{
THE DIALECTICS OF FUNCTIONAL AND HISTORICAL MORPHOLOGY IN THE EVOLUTION OF A CITY: THE CASE OF THE STONE TOWN OF ZANZIBAR
}

\author{
Mahbub Rashid, PhD, RA \\ Professor of Architecture, University of Kansas,1465 Jayhawk Boulevard, Lawrence, Kansas 66045 \\ E-mail: mrashid@ku.edu
}

\author{
Hadi Shateh \\ PhD Student, University of Kansas, 1465 Jayhawk Boulevard, Lawrence, Kansas 66045 \\ E-mail: hasshateh@ku.edu
}

\begin{abstract}
This paper reports a study of historical and functional morphology of the Stone Town of Zanzibar in Tanzania. The town is interesting because its mostly fine-grained physical fabric with an irregular street grid shows a remarkable degree of consistency despite the fact that it evolved under significantly different social, economic and political conditions. Therefore, the study of historical morphology was aimed at identifying if the town went through any structural changes despite its physical continuity; and the study of functional morphology was aimed at identifying the relationship between functions and the structure of the town.

For historical morphology, three street maps representing three distinct historical phases of the town were studied using the techniques of the axial map analysis of Space Syntax. For functional morphology, the relationships between the axial structure of the present day street grid and land use patterns, ownership patterns, building classifications based on ethnic influences, significant buildings and streetscape elements, and building conditions were studied explaining spatial distribution of functions in the town. The study found that the axial structure of this town had a diffused pattern of syntactic centrality that took different shapes in different phases of its development. The study also found that the axial structure of the town has been a strong force determining the present-day spatial distribution of functions in the town. Based on the findings, the paper then describes a dialectical relationship between history and function in the Stone Town.

By combining historical and functional morphology, this study provides a methodology for an enriched understanding of the morphological processes of growth and transformation of a city, in which historical and functional specificity of the city is complemented by a more generic description of the street network offered by Space Syntax. As a result, the study contributes to standard Space Syntax analysis that usually takes a synchronic view of cities and spatial structures for the sake of a more generic theory of urban form; and to historical research that usually consults any number of historical sources for the sake of a rich description specific to a historical reality, but does not analyze the spatial morphology of cities in a comparative or systematic way. With the enriched morphological perspective of this study, it may now be possible to describe precisely the socio-spatial and spatio-temporal processes, emphasizing the relationship between design and the politics of power, of other traditional cities that went through similar historical experiences, as did the Stone Town of Zanzibar.
\end{abstract}

\section{INTRODUCTION}

In morphological studies of cities, a distinction can be proposed between functional morphology that which is concerned primarily with the relationship between structure (form) and function, and historical morphology that which is committed particularly to studying historical pathways of structural change (or the transformation of form). Although there is, in practice, considerable overlap between functional and historical morphology, several issues can be identified in which the interplay between functional and historical analysis is likely to be particularly fruitful. 
The historical analysis of structural features of cities alone generally provides an incomplete picture of the city. Our understanding of the city, for example, is greatly enhanced if we can describe changes in structural patterns, as well as how these changes affect functions in the city. Are certain changes in the structure correlated with changes in functions? Are certain functions retained as primitive characters of a city, characters that go back to the early stages of its formation, despite changes in structure? Do certain structural changes permit new functions while also retaining some of the old functions, thus ensuring a sense of continuity?

With the help of functional and historical analysis one may also be able to define more precisely the historical sequences of both functional and structural changes that permit an understanding of how the city becomes constructed as a system. In order to understand the city and the factors involved in its construction, it is often useful to know the order in which it was constructed to help determine the interrelationships among parts. In a mechanical system, the order of assembly may often be reasonably inferred by the way in which parts fit together. But for a quasi-autonomous complex system like the city, the interrelationship among structural components alone may not be enough to explain how the city is put together.

Concerning functional and historical morphology, the Stone Town of Zanzibar in Tanzania (Figure 1) is interesting because for a town that had evolved under the influence of often conflicting Islamic and British colonial forces its mostly fine-grained physical fabric with an irregular street grid shows a remarkable degree of consistency (Figures $2 \& 3$ ). Unlike many other colonial cities, this town did not suffer any large-scale surgery reflecting colonial imperialistic ideals. Rather, it seemed to have made a smooth transition from its traditional Islamic atmosphere to a seat of colonial power and then to a post-colonial town. Based on this initial observation, three related hypotheses can be proposed in relation to functional and historical morphology outlined above:

Hypothesis 1: The Stone town of Zanzibar, which was built under Muslim rulers, went through several small changes during the colonial period. Though these changes were unable to alter its physical character, taken together they were sufficient to transform the structure of the town in a way that might have effectively served colonial purposes for a while. Therefore, instead of a polarized spatial system that we find in many colonial cities where a large-scale urban grid is often superimposed on a small-scale irregular grid, it is possible that this town has a continuous layout with a diffused pattern of centrality that took different shapes in different

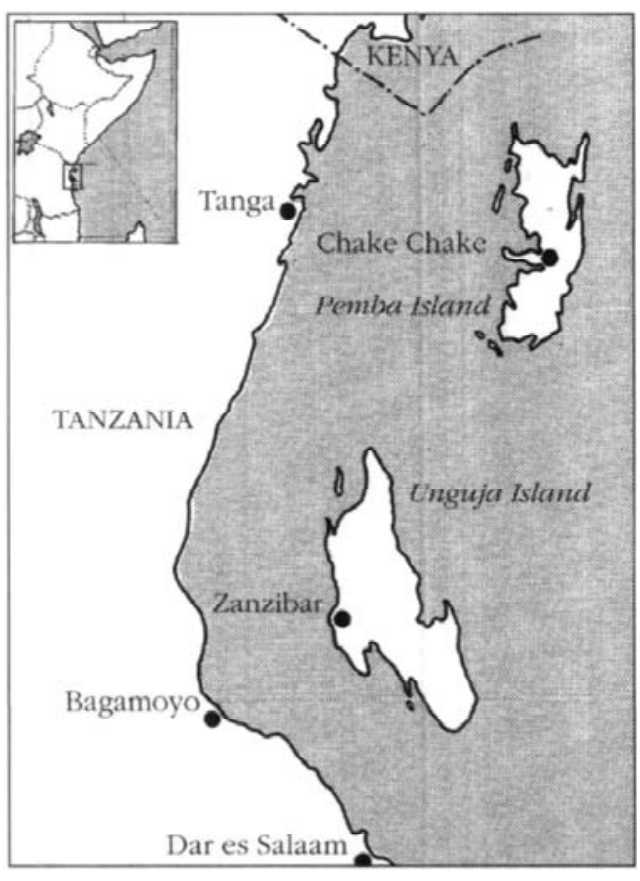

Figure 1: A map of the Zanzibar archipelago on the east coast of Africa, some forty kilometers off the northern coast of Tanzania . (Source: Siravo, 1996) 


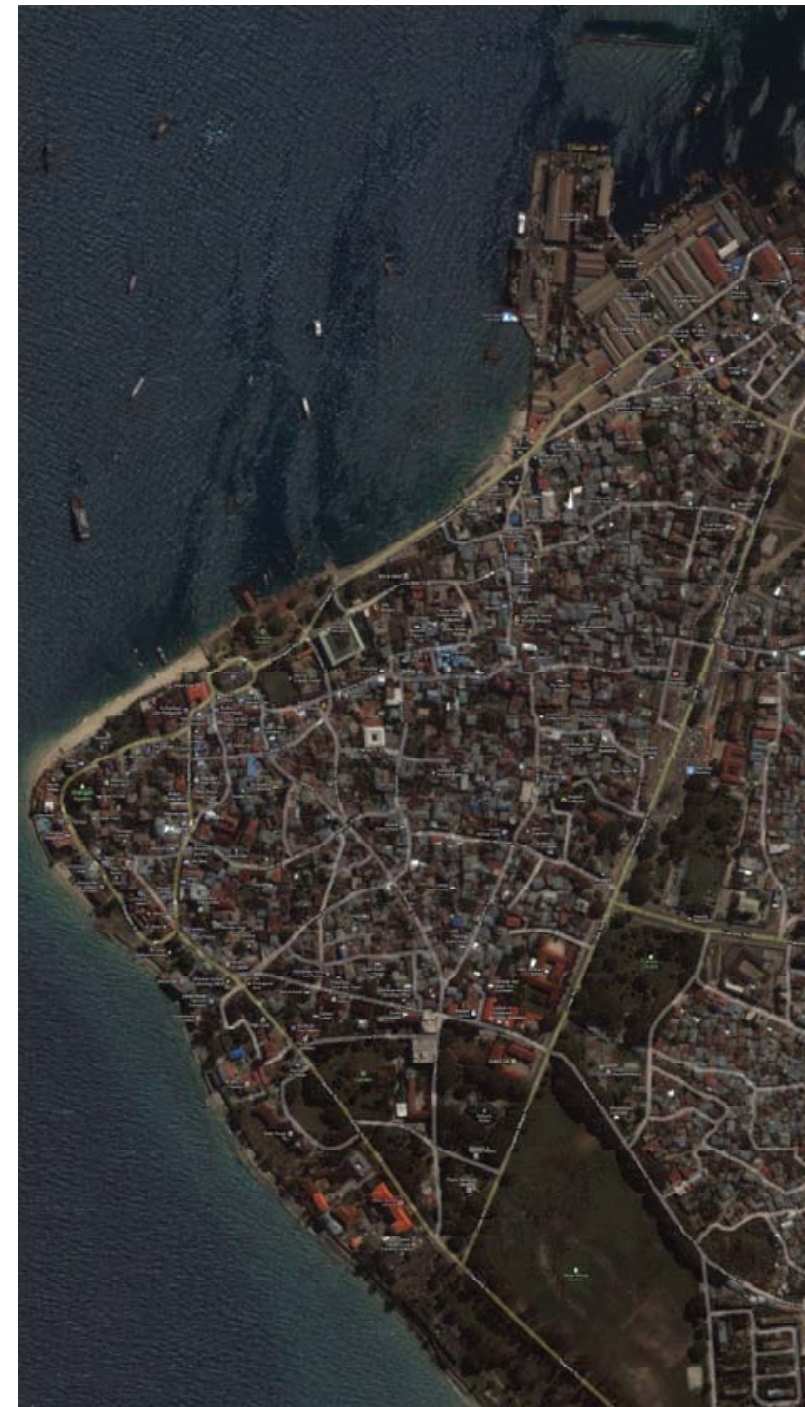

Figure 2: The Stone Town of Zanzibar as it is today. (Created using Google Map screen shots)

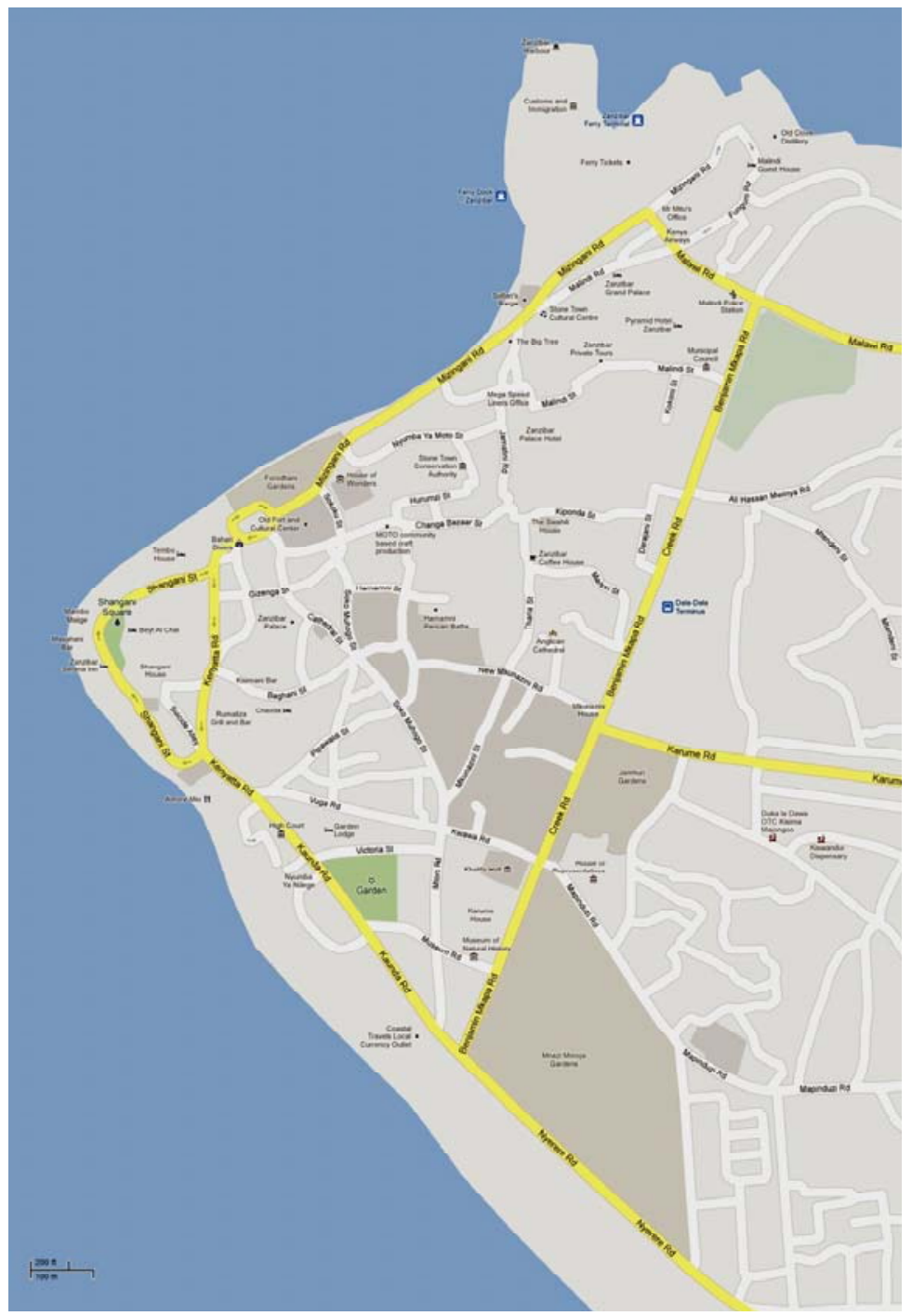

Figure 3: The street network of the Stone Town of Zanzibar as it is today. (Created using Google Map screen shots)

phases of its development.

Hypothesis 2: As the environment of the town changed from a traditional Islamic city to a city where traditional Islamic and Western colonial forces found a balance, the structure of this town also shifted from that of traditional Islamic cities to that of Western medieval cities with irregular grid. To reveal this shift, as a part of the analysis of historical morphology, the evolving structure of the town will be compared to the structure of traditional Islamic cities and Western medieval cities with irregular grid.

Hypothesis 3: Since the fine-grained physical fabric of the town shows a remarkable degree of consistency, it can be assumed that the town grew in an incremental manner taking advantage of its structure. Therefore, an analysis of functional morphology of the town at present should reveal a remarkable degree of structural dependency of functions.

Concerning this study, two additional factors also played some role in selecting the town as a case study. First, the town was small enough to do a more detailed analysis that was required by the kind of morphological study outlined above. Second, a considerable amount of historical and functional data on the Stone Town of Zanzibar was also relatively easy to find. However, techniques for retrieving structural data needed for morphological analysis outlined above has become available only recently. Since previous studies on urban structure 
that often used metric properties of street grid may be less useful for studying this town with irregular street grid [e.g., 1-4], this paper applies 'Space Syntax' theories and techniques to the analysis of the morphology of the town encompassing both its functional and historical morphology. In recent years, Space Syntax has been very successful in describing the structure of cities regardless of the geometrical order of street grid. Therefore, a brief introduction to Space Syntax is presented next.

\section{SPACE SYNTAX AND ITS SYSTACTIC MEASURES}

Space Syntax is a field of architectural study that focuses on the structure of space and its relationship with human functions in different types of built environment. The theoretical foundations for the descriptive techniques of Space Syntax were first laid down by Hillier and Hanson [5], and were later elaborated by Hillier [6]. Space Syntax argues that there is a reciprocal relationship between space and society, each shaping the other. This relationship is a statistical one in the sense that space, through its structure, provides opportunities for the society and it depends on the society to take advantage of these opportunities. Space Syntax also argues that the society often uses spatial structure unconsciously. Space Syntax, then, has made it one of its goals to bring spatial structure from its unconscious, non-discursive level to a conscious, discursive level through its analytic theories and techniques [6]. It has been able to do so by emphasizing the fact that an essential key to the understanding of the structure of any spatial system is the description of the way in which every space is accessible from all other spaces in the system, not in terms of metric distance but rather in terms of the number of changes of physical and/or visual direction needed to go from one space to all the other spaces.

A number of characteristics of its theories and techniques make Space Syntax a powerful research tool for studying the relationship between human functions and the built environment. First, it provides simple, analyzable diagrammatic representations of the environment that make intuitive sense. Second, it entails analysis of any one of its diagrammatic representations as a system, where each element is considered a part of the system. Third, it provides quantitative values to each element and to the system as a whole. Fourth, it provides ways to relativize these values based on the size of a system, thus making it possible to compare systems of different sizes. Finally, the theories and techniques of Space Syntax are not specific to any environmental type, hence can be applied to all different kinds of built environment.

Therefore, Space Syntax studies of urban systems exemplify a morphological approach to urban modeling based on rigorous description of the spatial structure of cities and its relationship with different kinds of functions. For its purpose, Space Syntax represents an urban system as an axial map, which is a network of the fewest and longest axial lines needed to cover every street and circulation ring in the system, in an attempt to capture the potential structure of visibility and access within the system (Figure 4). The patterns of connections, differentiation, and centrality of the axial map are then described using different syntactic measures [5].

How Space Syntax computes these syntactic measures can easily be illustrated visually by representing the axial map as a graph (Figure 4). In the graph, the axial lines are treated as vertices or nodes and their intersections as edges. In order to represent how a line is connected to the other lines in the system, this graph can be rearranged using the line as the root vertex and all other lines as vertices on successive layers defined based on the minimum number of lines one must use to reach them from the given line. The rearranged graph, also known as the justified-graph, will either look shallow with few layers if the line is well-connected to the whole system, or it will look deep with more layers if the line is poorly connected to the whole system.

One key syntactic measure of Space Syntax is integration. The integration value of an axial line indicates how well the line is connected to the network of lines in an axial map. A higher integration value of a line indicates stronger connection of the line to the network. The integration value, which is an algebraic function of the minimum number of lines one must take to go from a given line to every other line in the network, is also relativized to allow direct comparison between systems of different sizes [5]. The integration value of the system as a whole is given by the average of the integration values of the lines in the system. Again, the higher the integration value of a system the more connected the lines are within the system. 


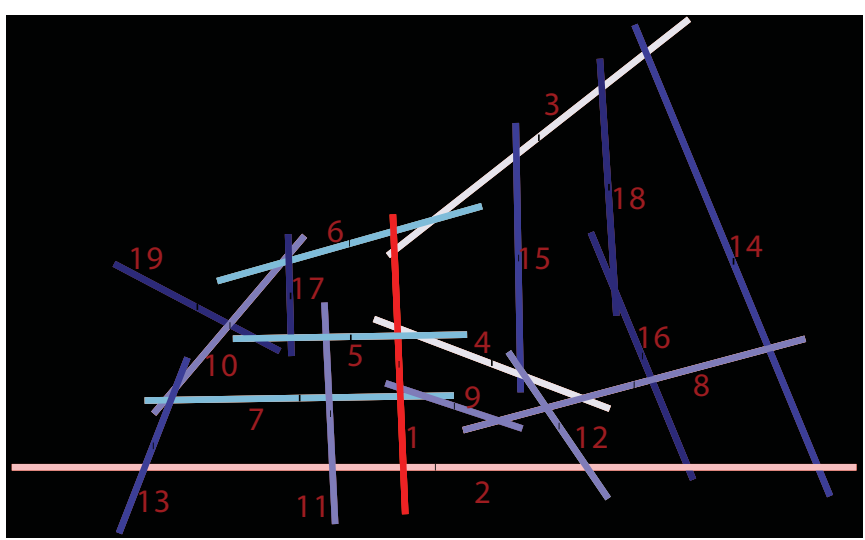

An axial map with numbered lines

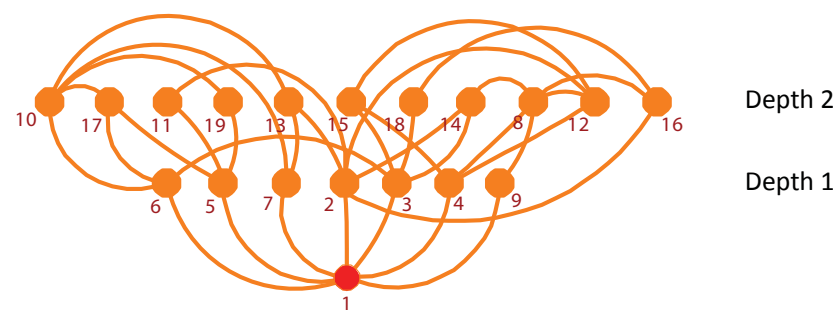

A justified graph from axial line -1 showing other lines at various depths

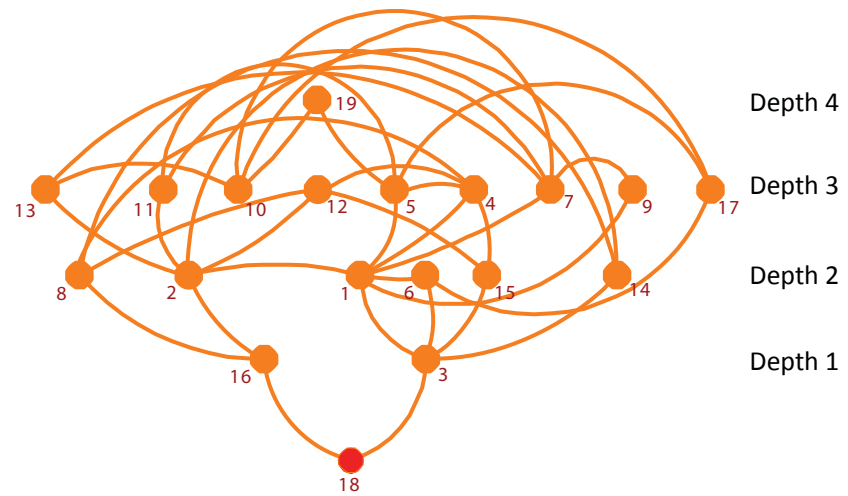

A justified graph from axial line -18 showing other lines at various depths

Figure 4: The techniques of the axial map analysis: (a) An axial map with the distribution of the integration value shown using color. In the colored map, color ranges from red indicating the most integrated lines to blue indicating the least integrated or most segregated lines. (b) The justified graph of axial line-1 with a high integration value shows that in order to get to any axial line of the map from this line only two steps are needed. (b) The justified graph of axial line-18 with a low integration value shows that in order to get to any axial line of the map from this line at least four steps are needed.

The syntactic centrality of an urban system can be visually represented by the integration core of the system. The core consists of the set of most integrated lines in the system. In a colored axial map, where color ranges from red indicating the most integrated lines to blue indicating the least integrated or most segregated lines, the set of red lines can conveniently be treated as the integration core of the system (Figure 4). 
Finally, the syntactic intelligibility of an urban system is defined as the correlation between the local and global syntactic properties of the system [6]. An urban system is considered intelligible when the correlation is strong. That is because in such a system we may be able to infer the global syntactic properties more easily using the local syntactic properties. One local syntactic property often used for the purpose is connectivity. The connectivity value of an axial line is the number of lines directly connected to the line in an axial map. In several urban studies, the integration values of axial lines within its local area are also used as a local property. Such an area may include only those lines that reside within a certain number of steps away from a line. For example, the integration value at radius-3 of an axial line uses only those lines that are three steps away for the given line. Statically, the syntactic intelligibility of an urban system is given by given by the coefficient of determination $\mathrm{r}^{\wedge} 2$ with a value ranging from 0 to 1 .

Using the techniques and measures of Space Syntax discussed above, historical and functional morphology of the Stone Town of Zanzibar was analyzed. Before the analysis and findings are discussed, a brief urban history of the town is presented next.

\section{A BRIEF URBAN HISTORY OF ZANZIBAR}

The Stone Town of Zanzibar has been among the most important East African coastal Swahili towns. Earlier, it was a triangular peninsula connected to the main island of Unguja by a narrow strip of land at the southern tip. Later, the creek separating the peninsula from the mainland was drained and filled-in in the 20th century (Figure 5).

Originating as a fishing village in the 12th century, the settlement soon became a typical Swahili state run by local dynasties. By the end of the 16th century, the local ruling dynasty of Zanzibar came under the hegemony of the Portuguese. Soon thereafter, the Omanis took control of the state. At this time, Zanzibar was still a tiny settlement. The town saw some significant growth and developments under the Omanis and became a bustling town by the last quarter of the 19th century. However, in the 1890s the British then took control of the town from the Omanis, and the town remained as a British colony until the revolution of 1964. Therefore, the urban history of the town can easily be broken down into three phases: 1) the early phase under the Omanis, 2) the British colonial phase, and 3) the post-colonial phase.

\section{The Early Phase}

The traditional maritime economy of Zanzibar, which depended primarily on commercial relations with the northern rim of the Indian Ocean, increased significantly by the 17th century under Omani protection, but the town itself did not see any significant physical change and/or growth. Thus, in 1799 it still had numerous huts with only a few stone houses [7].

By the early 19th century, a growing international maritime economy of Zanzibar included Europe and the Americas as well. Commodities passing through Zanzibar at the time included ivory, copal, hides, and slaves that originated from the mainland. This transit trade provided handsome profit to a large merchant class in Zanzibar [8]. Additionally, most commodities produced by plantations, especially cloves and coconuts, also passed through Zanzibar [8]. As a result, the importance of the town as an economic hub grew in the region. Zanzibar, however, became significantly more important when the Omani ruler, Sayyid Said, moved his court here from Muscat in 1832. Within a decade or so, the Americans, the British, and the French opened consulates in the town in response to its growing political importance. Consequently, the town saw a considerable amount of building activities. Palaces, harems, mosques and, eventually, country houses were built for the royal family; residences and warehouses for consuls and merchants; houses with shop-fronts or shops for local shopkeepers; permanent quarters and better defenses for the army; and a customs house, sheds and offices were built for the administration (Figure 6).

In 1846, Charles Guillain, a French naval captain, documented the rapid growth of Zanzibar in the first half of the 19th century in his map (Figure 5). The map showed blocks of large stone houses and palaces along 


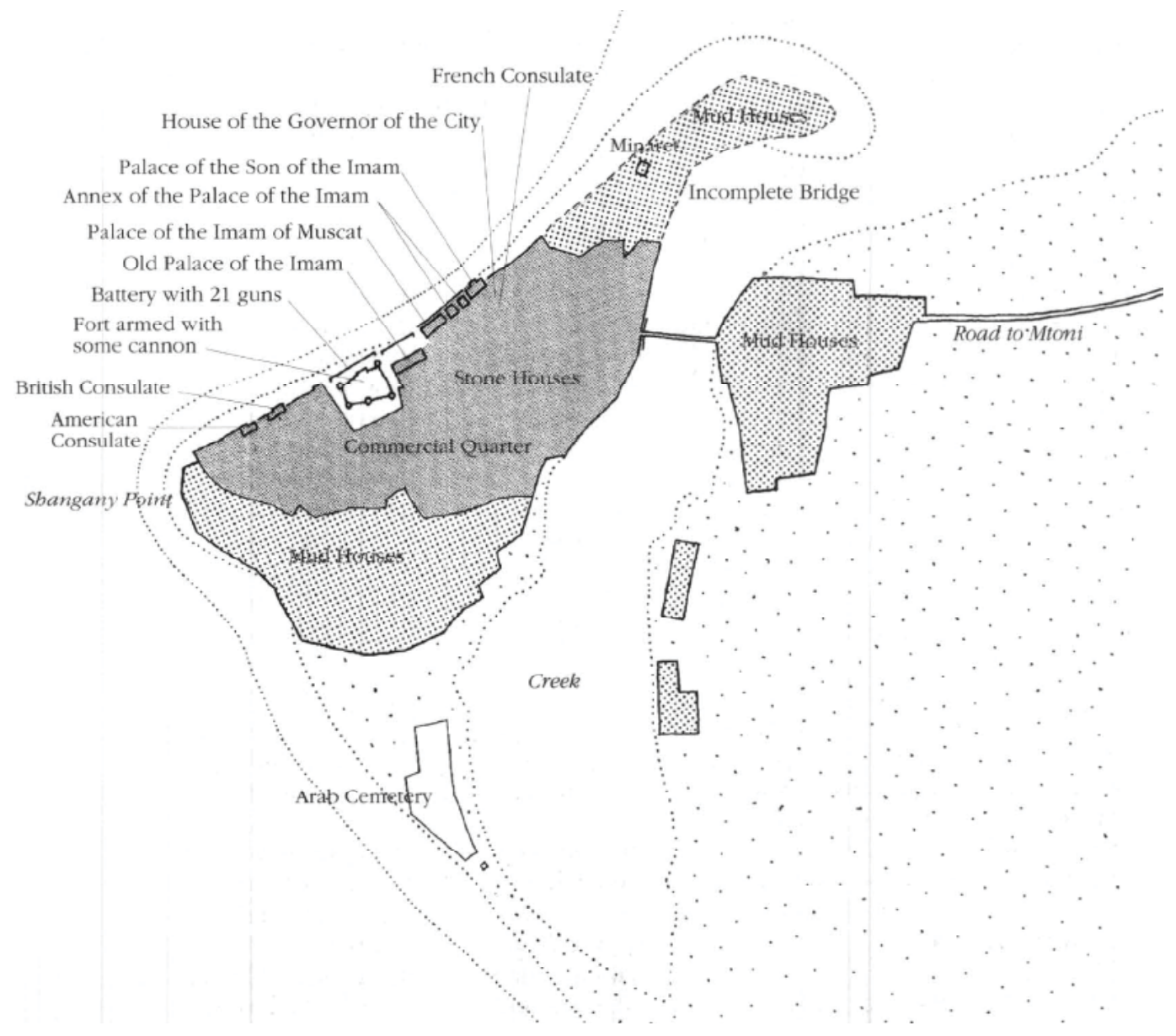

Figure 5: A sketch plan of Zanzibar based on Captain Charles Guillain 's map of 1846. This map is the earliest record of the town to survive. It shows an established stone town surrounded by mud and thatch houses, which covered most of the peninsula and spread across the creek at the narrowest crossing point. (Source: Siravo, 1996)

the seafront. It also showed the Sultan's palace and flagpole, the residences of his son and that of the Governor of the town, as well as the American, British and French consulates. The part of town behind the seafront, indicated as the commercial quarter, had a complex of bazaar streets in the map. The town extended all the way to the creek on the east. In the map, the edges of the town to the south and north were occupied by mud structures. Many of the more durable houses of the stone town shown in Guillain's map were owned by Omani Arabs, who numbered 300 in the 1770 s and 1,000 in 1819, increased rapidly to 5,000 by the 1840 s. Although the smaller Omani Arab landowners probably lived on their plantations in the countryside, the more prominent ones preferred to have their mansions in the town for socio-political more than economic reasons. They built their houses around the palace complex and towards the western tip of the peninsula. Later, they also expanded to the southern half of the peninsula.

In contrast to the landowning Omani Arabs, the Arab and Swahili merchant class settled in the older central and northern sections of the town. As the Arab and Swahili section of the merchant class began to wane in the latter half of the 19th century, the Indian section of the class began to increase. Within half a century between 1819 and the 1870s, the Indian population had grown about 15-fold, from 214 to nearly 3,000. Many of them built large residences in the bazaar area behind the sea front. By 1860 new quarters were being established 


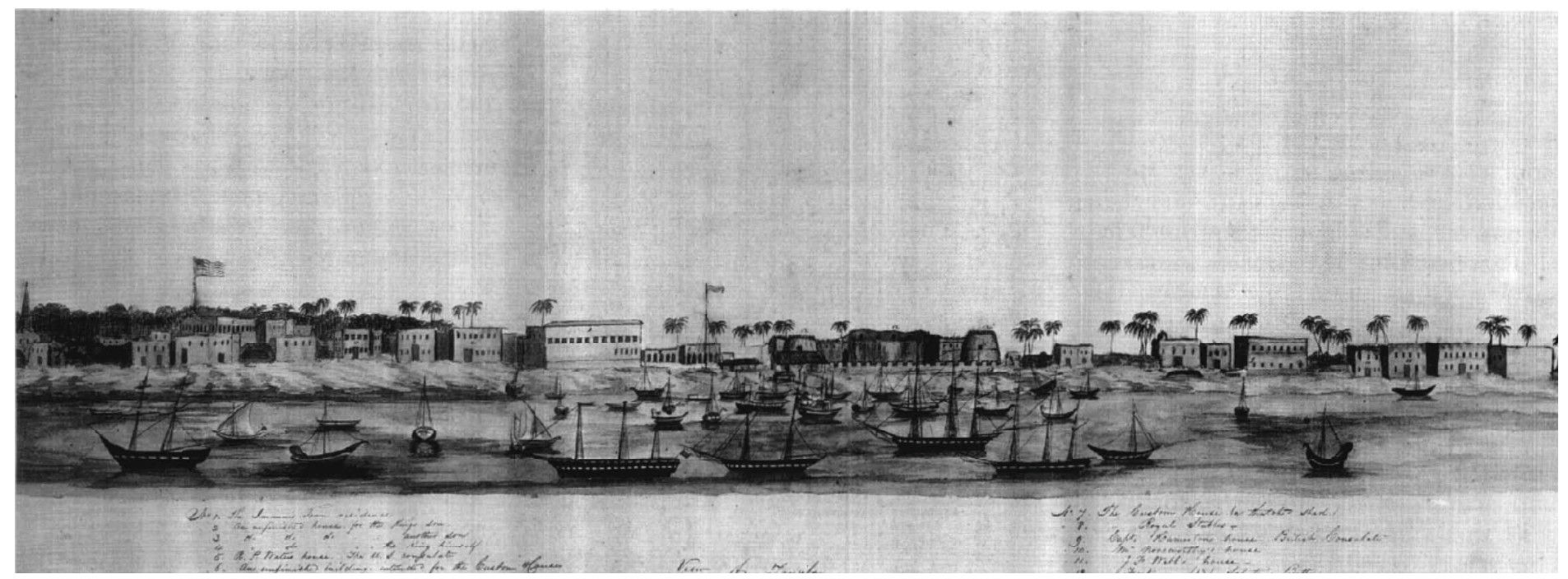

Figure 6: A watercolor of Zanzibar's seafront, painted by an American visitor circa 1845, entitled "View of Zanzibar." The buildings are numbered and listed in the legend as: 1. The Immam's Town Residence. 2. An unfinished house for the King 's son. 3. An unfinished house for another son. 4. An unfinished house for the King himself. 5. R. P. Watis house. The U. S. Consulate. 6. An unfinished building intended for the Custom House. 7. The Custom House in thatched shed. 8. Royal Stable. 9. Capt. Hamerton 's house. British Consulate. 10. Mr. Mossworthy's house. 11.]. F. Webb 's house. 12. Fort. 13. Saluting Battery. The minaret of the Mnara mosque, though not listed, is shown at the far left. Courtesy: Peabody Essex Museum, Salem, Massachusetts. (Source: Siravo, 1996)

in the town largely inhabited by Indian merchants [9].

Besides the landowners and the merchant class, the third important class of the town was the emerging working class connected with the commercial economy of the port. Throughout the 19th century they lived in the Stone Town. In 1870s, Christie noted 'negro huts are not confined to any distinct part of the city'.cited in 10 The first detailed survey of the 1893 revealed a surprisingly large number of huts among the stone houses in the town [9]. Only in the late 19th and early 20th century, they moved on the other side of the town across the creek, known as Ng'ambo. The creek was crossed on foot at low tide, but in 1838 a weak bridge was completed across it.

Until 1870, Zanzibar had grown steadily but haphazardly. The third Sultan, Sayyid Barghash, who reigned from 1870 to 1888 , took a more active interest in the town itself and initiated a number of public improvement projects, including roads, an aqueduct to bring water into the and several important new buildings. During his reign, Sultan Barghash built the public baths, and doubled the size of the customs sheds along the seafront, filling the space where the battery had stood in front of the Fort. He also gave the seafront a dramatic face-lift with the addition of a lighthouse and the imposing ceremonial palace, the Beit al-Ajaib. In addition, the Sultan built a huge boat-shaped tank in front of the palace to provide his citizens with clean water. There was now also a small electricity plant to provide the tower and palace with electric light. Thus, by the 1890s the town had grown into the cosmopolitan center of the western Indian Ocean [7].

In 1892, the Survey of India was commissioned to survey Zanzibar and to make a map accurately showing the street pattern and the different mitaa (i.e., neighborhoods) of the town (Figure 7). The most striking change, when comparing the 1892 survey with the situation recorded by Guillain in 1846, is the overall growth of the town. Zanzibar had spread substantially in all directions. Like Guillain's map, the 1892 map also identifies the important buildings along the seafront and within the Stone Town. Significant changes include, among other things, the buildings built by Sultan Barghash. Additionally, the map also shows four more consulates - Belgian, German, Italian and Portuguese - which had been established in the 1870s and 1880s, as well as a number of new civic buildings foreshadowing the larger public buildings to come early in the next century. The 


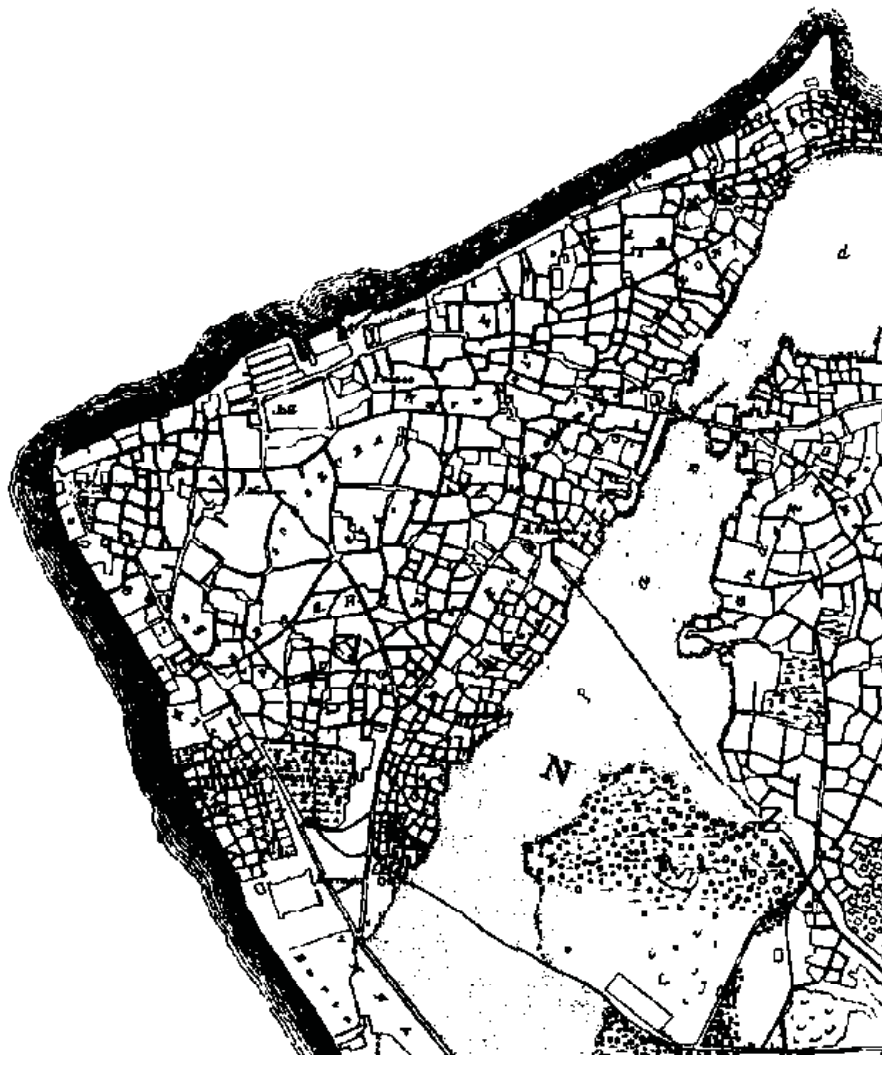

Figure 7: A 1892 Map of Zanzibar drawn by the Survey of India. (Source: Siravo, 1996)

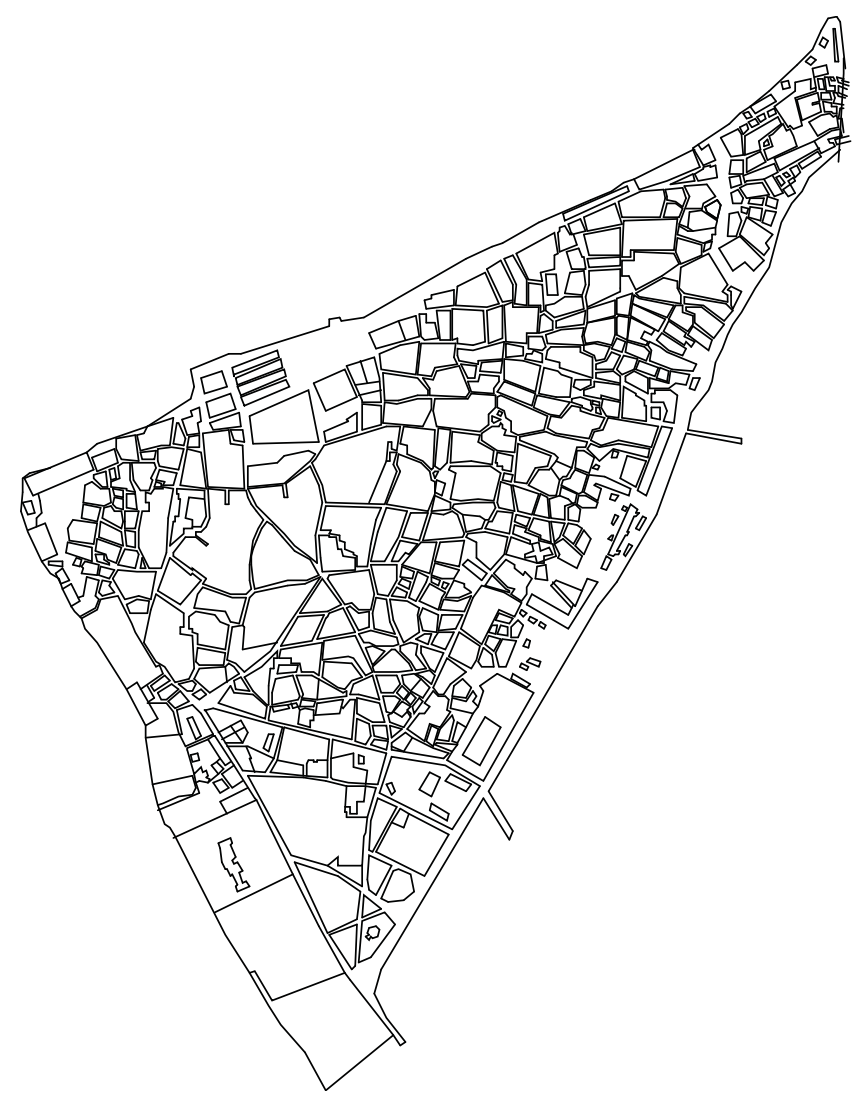

Figure 8: A 1922 Map of Zanzibar. (Source: Garth Myers)

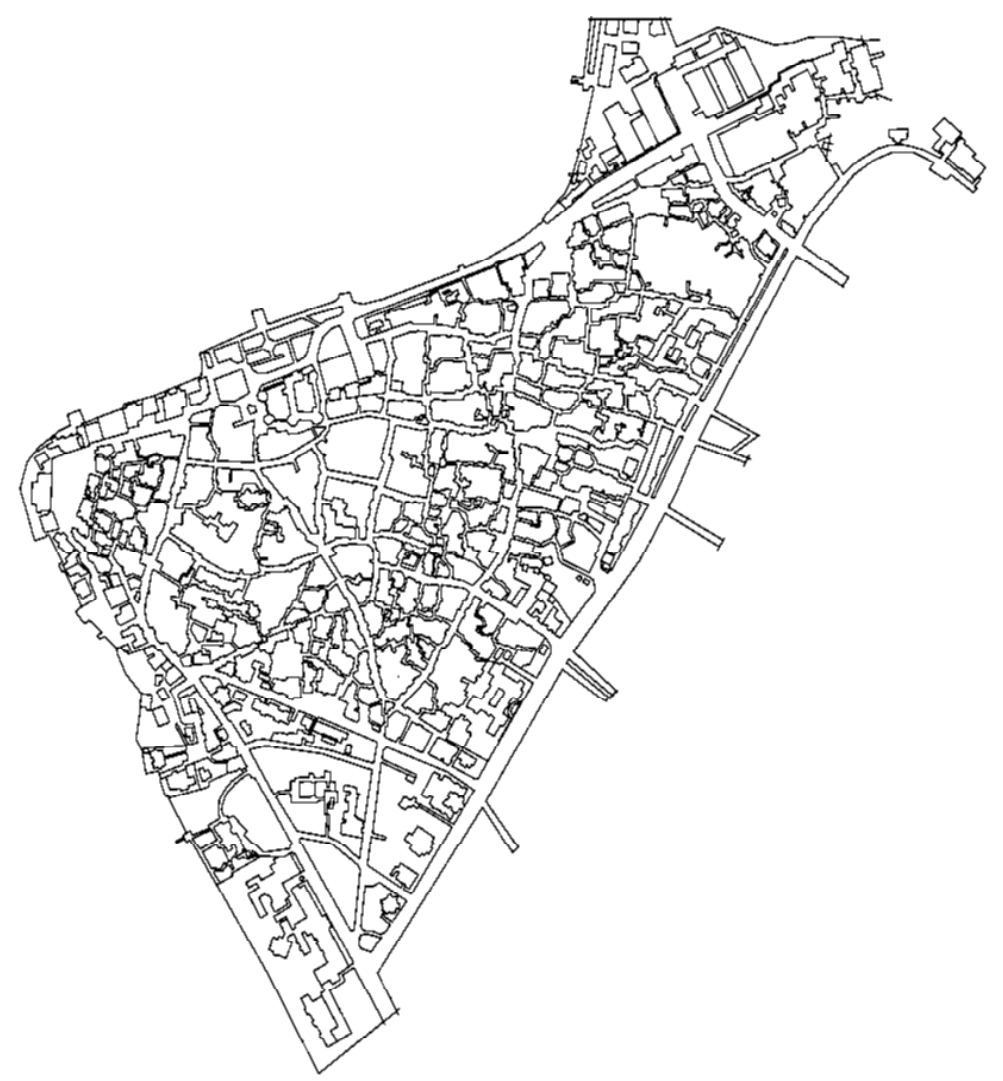

Figure 9: A Map of Zanzibar at its present stage. (Drawn based on a 1996 map by Giovanni Tombazzi) 
Anglican cathedral completed in 1890 was another very visible change in Zanzibar's townscape. In spite of many transformations still to come, a comparison of the 1892 map with a plan of present-day Zanzibar demonstrates how little the street pattern within the central area of the Stone Town would change over the next hundred years.

\section{The Colonial Phase}

In 1890 Zanzibar was proclaimed a British protectorate, and with that the Omani era ended in Zanzibar. For the next sixty years or so, the building activity that would occur under a British administration started with the construction of a new Residency and the Law Courts at the southern edge of the town, the Central Market along the creek on the eastern side, and a new post-office on the main street, today's Kenyatta Road. During the same period, the Vuga South district was laid out and developed as a European quarter at the southern edge of the town incorporating Victoria Gardens. The broad avenues and green areas of the development provide a sharp contrast with the compact and very urban character of the Stone Town.

Among a number of public infrastructure projects that started in the early 20th century under the British supervision, the most ambitious was the gradual filling of the creek, which was not completed until the 1950s. The upper reaches of the creek were drained and opened as a public recreation area in 1915. The rest of the creek was progressively reclaimed. Today, the creek may still be recognized in the form of Creek Road and the adjacent open areas separating the Stone Town from the Ng'ambo area. Other projects built at this time included the construction of a new section of the Government Hospital in Vuga, a number of public schools, several clubs, two cinemas and the Peace Memorial Museum in 1925.

Significant changes also occurred at the northern end of town. In the 1920s, a new deep water wharf and cargo handling and storage facilities were built. With the creation of the new port, the shape of the waterfront itself was significantly altered. Because of the new landfill, the large mansions that had stretched all the way to the point were also demolished. Many of these changes made in the colonial era were recorded in a 1922 map of the town (Figure 8).

In the 1930s and after, several less visible changes were made to the older section of the Stone Town. Sultan Barghash's aqueduct was replaced by a modern pipeline and the water supply supplemented from other sources. Standpipes were put in throughout the old town to replace the existing wells, and a sewer and drainage system installed. Also, many of the narrow streets within the town were paved. A few buildings were demolished, and the corners of a great many more trimmed to improve the flow of traffic by widening roads. A new connection was created to allow vehicular traffic to reach the other side of the Stone Town through Shangani Street and Kelele Square, thus relieving some of the congestion in Kenyatta Road. Finally, in the northern part of the town, a new road extending Creek Road north was constructed (the present Bwawani Road) as part of a proposal to reclaim Funguni basin, which was never completed.

\section{The Post-Colonial Phase}

With the economic and social changes after the 1964 Revolution, the Stone Town began a steady course of decline and deterioration, while considerable growth and transformations have taken place in areas on the other side of the creek, now marked by Creek Road. And, it was not until the 1980s that the introduction of a significant and growing number of large and ill-proportioned structures-some are new buildings, but most are traditional buildings that have been subjected to an incremental process of change-has determined the process of decay and widespread deterioration of the Stone Town.

In 1982, action to preserve Zanzibar's historic Stone Town began effectively when the United Nations Centre for Human Settlements (UNCHS/ Habitat) undertook a comprehensive study of the historic area and recommended appropriate measures to prevent its deterioration. The initial study was completed in 1983, and was followed by a more detailed report entitled Strategy for Integrated Development in 1984. Although important in stimulating further interest in the Stone Town, the recommendations of the Habitat report were not integrated in 
a comprehensive planning scheme and were therefore never formally adopted.

In recognition of the Stone Town's significance, in 1994 the Zanzibar Government initiated preparation of a conservation plan to reverse the decline and guide future development in the historic area. The Plan was prepared over a period of two years, as a joint initiative of the Stone Town Conservation and Development Authority and the Historic Cities Support Program of the Aga Khan Trust for Culture, and was formally adopted by the Zanzibar Government in 1994 [7]. As a part of the Plan the town was surveyed and the conditions of town at the time were recorded in detail, which were used as a part of the analysis of functional morphology of the town in the study reported below (Figure 9).

\section{FROM THE PAST TO THE PRESENT: ANALYSIS OF HISTORICAL MORPHOLOGY OF THE TOWN}

The study of historical morphology aiming at understanding the transformation of the structure of the Stone Town were based on the following three street maps representing the three distinct phases of the town noted above: 1) the map of 1892 showing predominantly the Islamic phase of the town (Figure 7); 2) the map of 1922 showing modifications made to the town under the colonial power (Figure 8); and 3) a map showing the present stage of the town (Figure 9).

The axial structures of these maps are given in Figures 10 - 18. These structures are colored using integration values of the axial lines calculated at radius-n, radius-5, and radius-3. Recall that radius-n includes lines up to the number of steps required to go from any line to any other line within the system, radius-5 includes lines only up to five steps away from each line, and radius-3 includes lines only up to three steps away from each line. The colors indicating the distribution of integration values ranges from red for the most integrated lines to blue for the most segregated lines. A summary of the syntactic values of these maps are given in Table 1. The table also contains some syntactic values of a set of Iranian cities representing traditional Islamic towns and a set of English towns representing medieval western towns, which are taken from Karimi [11]. The following observations are made based on these colored axial maps and their syntactic values.

\section{The axial structure of the 1892 map}

The axial structure of the 1892 map, colored using radius-n integration values, shows the axial lines on the western seafront of the town as the most integrated set of lines (Figure 10). Recall that this area, which was the interface between the town and its sea-going vessels, was the most commercially active area during the Islamic phase of the town. The integration core of the town, defined by this set of most integrated lines, also seems to extend to what was then the market area of the town. Soon after the market, the core gradually diffuses itself in a continuous pattern toward the less integrated but more privileged residential areas of the town. Gradually, the axial structure becomes more and more segregated as it approaches the eastern side of the town, where the socially disadvantaged working class used to reside at the time, just next to the shallow creek. Also recall here that the other side of the creek, known as Ng'ambo, was where the more permanent residential quarters for the working class of town were located. This pattern of gradual diffusion of the integration values in the axial map, thus, helps define the western seaside as the 'front' of town that interfaced with the world outside and the eastern side as the 'back' of the town that interfaced with the world less desirable.

The axial structures of the 1892 map, colored using radius-5 and radius-3 integration values, also show the axial lines on the western seafront of the town as the most integrated lines, but in each of these cases two additional syntactic centers of smaller reach can also be identified (Figures 11 \& 12). These two newly emerged syntactic centers, however, are better formed in the axial structure defined by radius-5 integration values. A pattern of gradual diffusion can also be observed concerning each of these syntactic centers. What is more interesting is the fact that the two newly emerged centers are located more toward the eastern-side of the town, suggesting that they might have very well served as the local interface between the rich and the poor of the town. This 


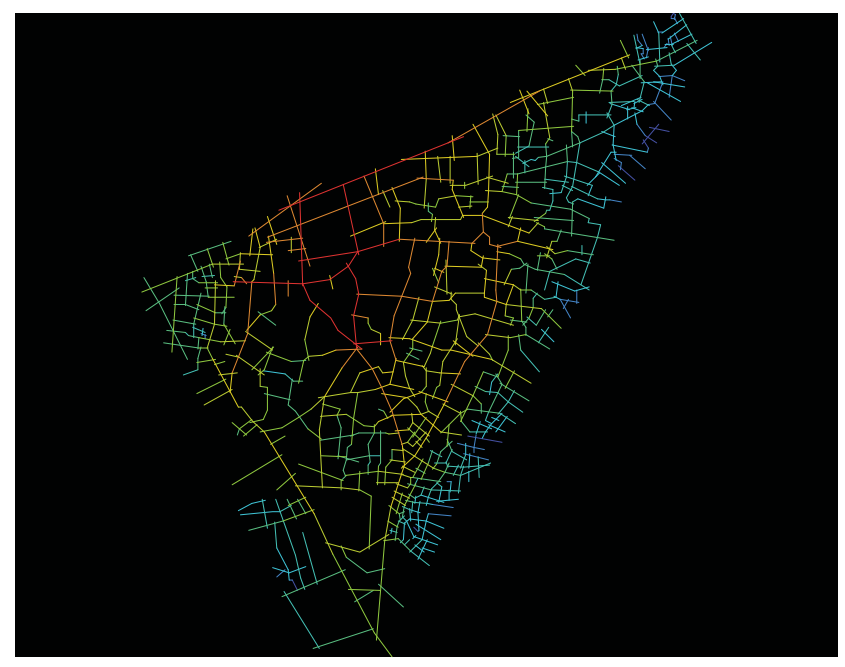

Figure 10: The axial map of 1892 with the distribution of the radius-n integration value shown using color.

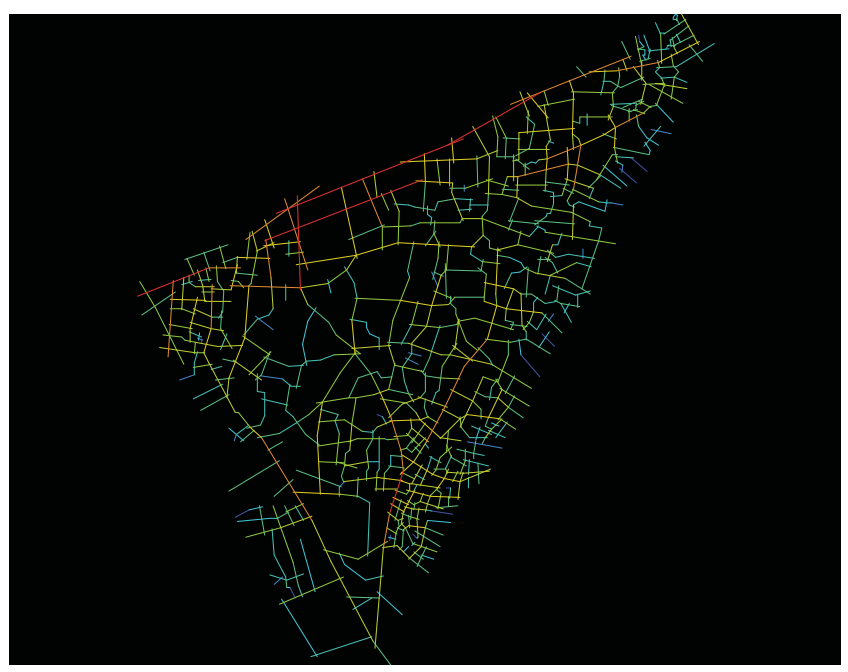

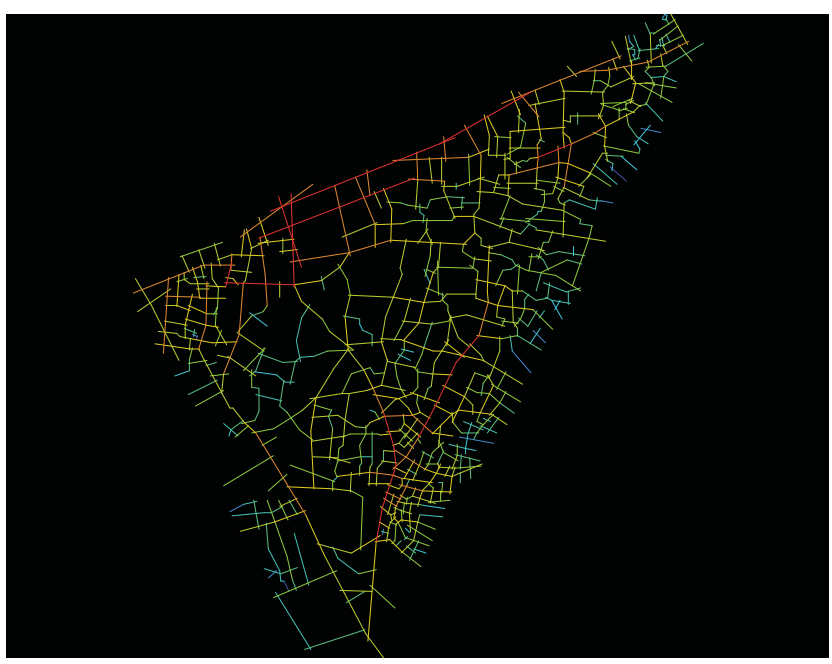

Figure 11: The axial map of 1892 with the distribution of the radius-5 integration value shown using color.

Figure 12: The axial map of 1892 with the distribution of the radius-3 integration value shown using color.

observation is interesting because when the British took control of the town in the 1890 they had focused more on this class divide than anything else through their spatial interventions.

\section{The axial structure of the 1922 map}

The axial structure of the 1922 map, colored using radius-n integration values, shows the axial lines on the eastern side as the most integrated lines of the town (Figure 13). The lines on the western side are still integrated, but not as much as the lines on the eastern side are. In simple words, the integration core of the town has shifted from the western side to the eastern side of the town. How did this happen?

The British, after they took control of the town in the 1890s, found it more advantageous not to upset the established social institutions of the town, which included the so-called Omani ruling class of the town. Therefore, instead of focusing on changing the existing ruling urban culture which had traditionally used the western side of the town, the British took hold of the south side of town, known as Vuga, for their use. They demolished the existing mud houses in the area in order to build their residential and administrative complexes. The axial structure of the 1922 map shows very little of the area because it included mostly enclosed compounds.

Far more important for the structure of the town, however, was the British move to integrate the working class of the town within the urban system, who was so far kept isolated on the eastern side of the town, as well as on the other side of the creek. For this, they created Creek Road along the edge of the existing creek 


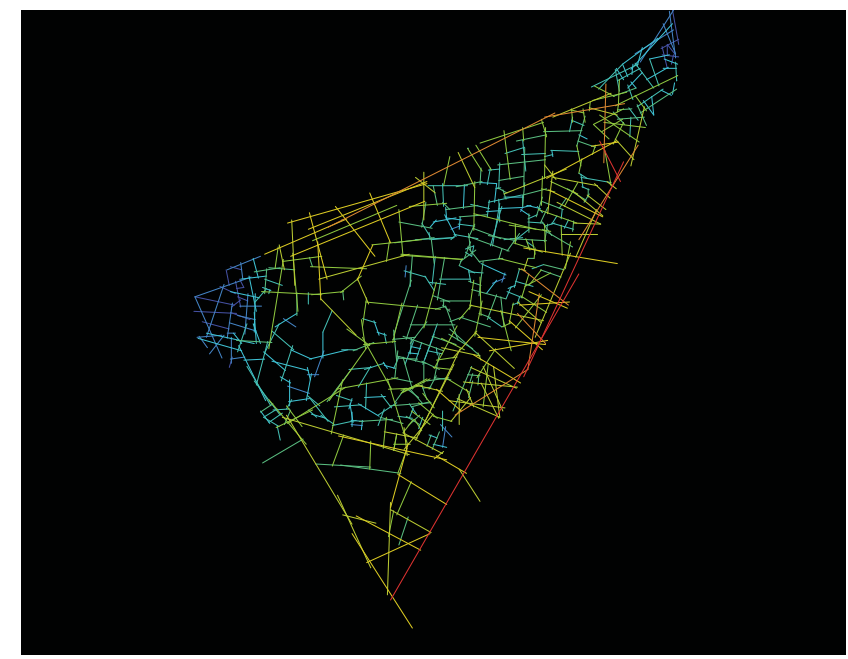

Figure 13: The axial map of 1922 with the distribution of the radius-n integration value shown using color.

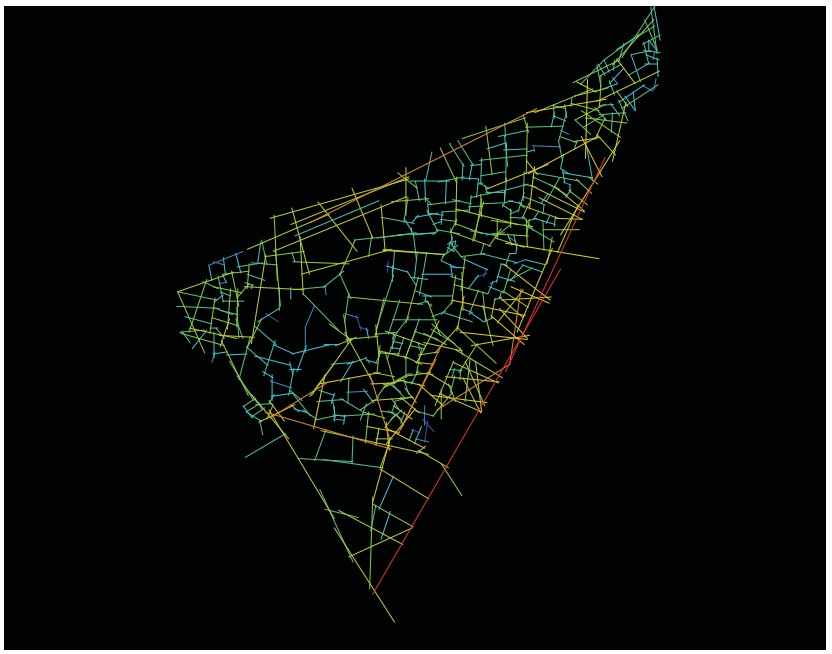

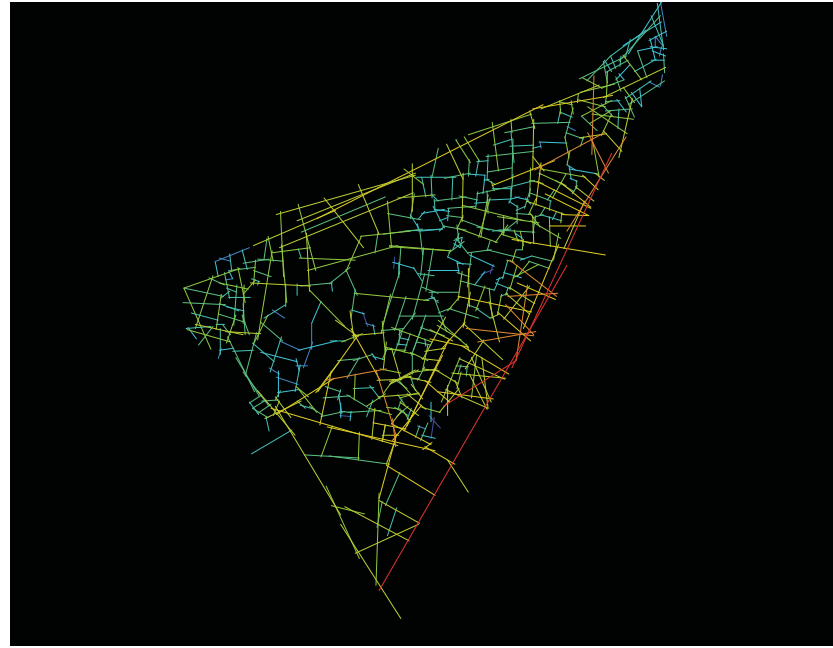

Figure 14: The axial map of 1922 with the distribution of the radius -5 integration value shown using color.

Figure 15: The axial map of 1922 with the distribution of the radius-3 integration value shown using color.

and made plans to drain the creek, fill it up, and make it an open space for all. This open space, which includes the Mnazi Mmoza Gardens and Jamhuri Gradens, has now become the heart of the greater Zanzibar bringing together inhabitants from the both sides of the town. It took a while for the British to complete the project, but with Creek road in place the British were already able to create an alternate syntactic center for the town by 1922. Over time, the area around this center would also become the area where the British would build most in terms of public infrastructure including schools, hospitals, transportation hub and, of course, gardens.

Additional important characters of British spatial interventions become clearer when the axial structure of the 1922 map is colored using radius-5 and radius-3 integration values (Figures 14 \& 15). The two syntactic centers that were observed on the eastern side of the 1892 map (Figures 11 \& 12) are no longer read as independent centers in the 1922 maps. Instead, they are now assimilated within a more pervasive syntactic core that starts at Creek Road on the east and reaches far inside the residential core of the Stone Town. In contrast, the reach of the syntactic core on the seaside has become much restricted in these maps. In other words, through a simple move of adding a street on the creek side of the town, the British were able to create a powerful syntactic center that would eventually become the 'functional' front of the town, and would reduce the western seaside to a mere 'symbolic' front with all the historic buildings. This also might have helped eliminate social inequity that existed in the spatial structure of the 1892 map. 


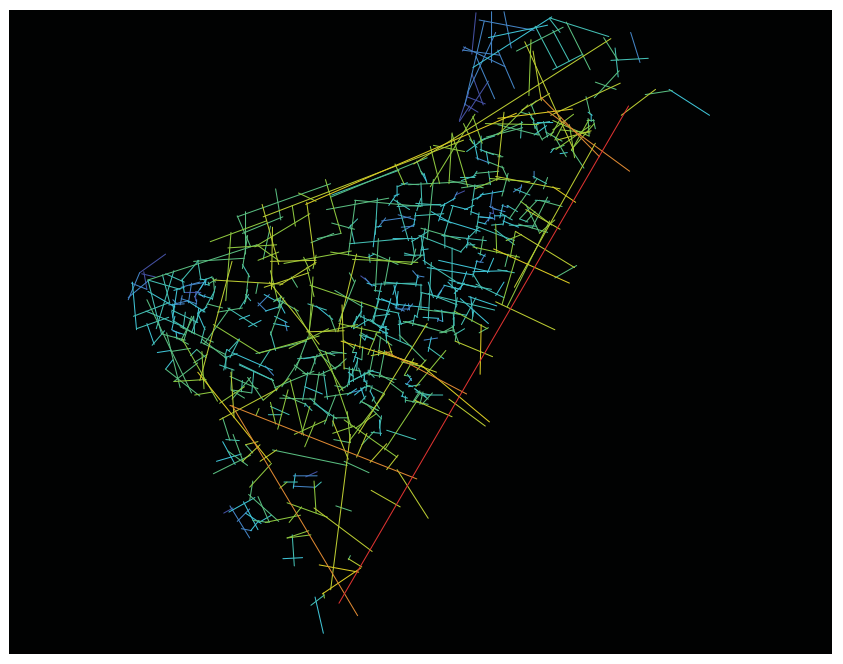

Figure 16: The axial map of the Stone Town at present with the distribution of the radius-n integration value shown using color.

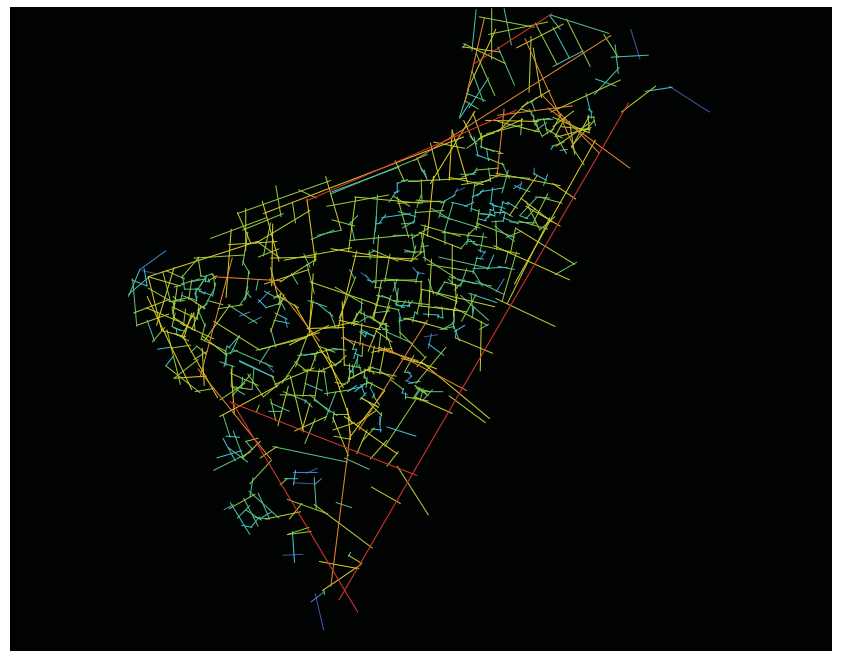

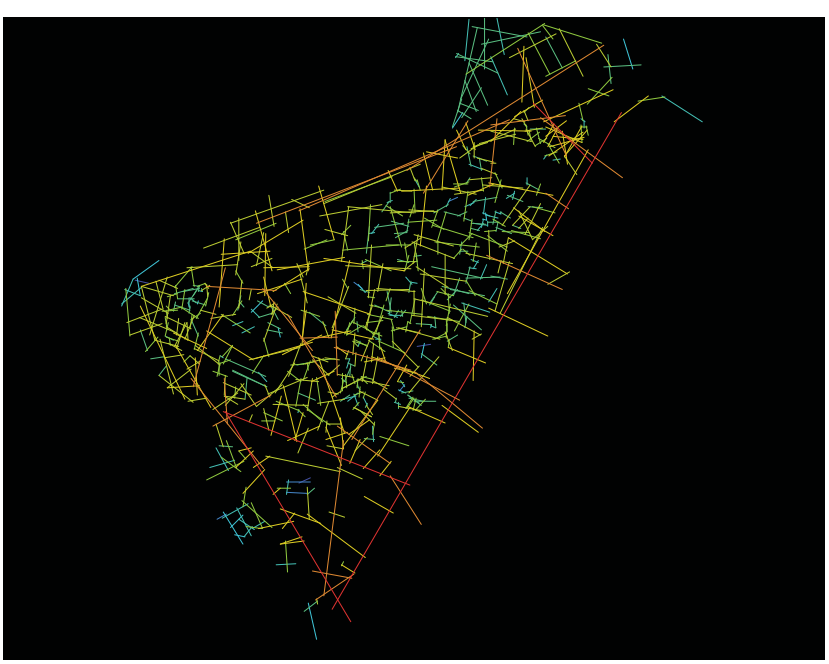

Figure 17: The axial map of the Stone Town at present with the distribution of the radius-5 integration value shown using color.

Figure 18: The axial map of the Stone Town at present with the distribution of the radius-3 integration value shown using color.

The axial structure of the map showing the present stage of the town

Today, the syntactic core of the axial map reads more like a wheel around the town with extended arms reaching into the heart of the town (Figure 16). Creek Road still remains as the most integrated line in the town, but the integration core around it seems to be much less pervasive than it was in the 1922 map. Rather, it can be observed that few of the more-integrated lines that originate here at Creek Road reach out, through the fabric of the town, to the other side of the town. A somewhat clear spatial separation between the western and the eastern syntactic core of the town observed in the 1922 map does not exist in the present map.

The wheel-shape axial core seems to be the consequence of several minor spatial moves. These moves included straightening up of Kaunda Road and Kwawa Road on the south side of the town and opening up of the Vuga area for public access and movement. As a result, these roads become powerful integrators between the east, south, and the west side of the town via Kenyalla Road all way up to the Mizingani Road on the western seaside. On the northern tip, Malawi Road connects Creek Road on the east to Mizingani Road on the west. This road becomes a major integrator because of the developments that occurred on the northern tip since 1922. To summarize, the wheel-shape integration core now includes Mizingani Road on the west, Makawi Road on the north, Creek Road on the east, Kaunda Road and Kwawa Road on the south, and Kenyalla Road on the southwest corner of the town (Figure 3).

Also interesting to note that the old market area at the geographic center of the town, which was clearly 


\begin{tabular}{|l|l|l|l|l|l|l|l|l|}
\hline & $\begin{array}{l}\text { Total } \\
\text { Number of } \\
\text { Lines }\end{array}$ & Mean Conn & Mean Int-Rn & Mean Int-R3 & Mean Int-R5 & $\begin{array}{l}r^{2} \\
\text { Int-Rn v. } \\
\text { Conn }\end{array}$ & $\begin{array}{l}r^{2} \\
\text { Int-Rn v. R3 } \\
\text { Int-Rn v. R5 }\end{array}$ \\
\hline 1892 map & 837 & 3.065 & 0.599 & 1.488 & 1.215 & 0.093 & 0.229 \\
\hline 1922 map & 687 & 4.602 & 1.009 & 1.955 & 1.539 & 0.368 & 0.635 \\
\hline Present map & 830 & 4.822 & 1.113 & 2.015 & 1.596 & 0.297 & 0.610 \\
\hline Iranian Cities & & 2.772 & 0.482 & 1.602 & & 0.116 & 0.160 \\
\hline $\begin{array}{l}\text { English } \\
\text { Towns }\end{array}$ & & 3.458 & 0.965 & 2.028 & & 0.264 & 0.428 \\
\hline
\end{tabular}

Table 1: important syntactic values of the axial maps of the 1892, 1922, and the present Stone Town Zanzibar. The table also includes the same values for comparable Iranian and English towns reported by Karimi (1997).

picked up by the integration core of the axial map of the 1892 map but was not picked up by the integration core of the 1922 map, is again picked up by the inner part of the integration core of the axial map of the present day map. This happens primarily because of the widening of some of those streets that extend from the outer wheel of the town into this area. Notable among them are New Mkunazini Road, Soko Muhogo Street, and Baghani Street (Figure 3).

In addition, it can also be noted that even though the radius-n axial structure of the present day town still shows some segregated inner areas, these areas get more integrated but less differentiated in the radius- 5 and radius-3 axial structures of the town (Figures 17 \& 18). In other words, as a result of widening and straightening up of several streets, the social logic that helped create the town gave itself away to another logic that would generally promote movement and control more than a social life requiring a nuanced differentiation in the axial structure.

\section{A comparison of the evolving axial structure of the Town with that of traditional Islamic cities and western} medieval towns

A comparison of the evolving axial structure of the Town with that of traditional Islamic cities and western medieval towns is needed to understand how British Colonialism had changed the traditional urban order of the Stone Town of Zanzibar. The writings of Eric Dutton, the chief secretary of the colony in the post war era, who helped plan several British colonial projects in Africa including many in Zanzibar between the 1920s and 1950s, provide us some indication of the grand vision British colonial urban policies had in Africa. For example, concerning the comprehensive town plan of Nairobi that he helped Walton James develop in 1926, Dutton wrote that the plan would result in a Nairobi "laid out with tarred road, with avenues of flowering trees, flanked by noble spaces and stately squares; a cathedral worthy of faith and country; museums and galleries of art, theaters and public offices” [12:1-2 cited in 13:195]. This urban vision based on a visible hierarchy of spatial order did not resonate well with African people, who had a 'fused' sense of space [14, 15]. As a result, as Alexander [16:2] points out, in much of Colonial Africa "new environments were created... [that] overlooked the social, symbolic and political meaning of the built environment of the indigenous villages and towns”.

At the core of this African 'fused' sense of space was the lack of a fixed distinction between outside and inside, and between the private and the public. Although the houses in the residential core of the Stone Town and other urban areas had something of an "intimacy gradient” between mostly female inner and mostly male outer rooms $[17,18]$, in practice gender distinctions in domestic and its more immediate urban spaces were more flexible than any rigid spatial hierarchy would imply $[13,19]$. Further, the urban spaces and streets in the Town historically were narrow and irregular, but vibrant with both male and female residents’ activities. As a 
result, one never felt the limit between the street and the house as something definite in a neighborhood of the Town [20]. However, narrow, tortuous streets of the Town also gave it a complexity that appeared rather incomprehensible to foreigners. Thus, for many colonial officers this was a place where they "were up against tradition the whole time" [21 cited in 13:200]. Quite understandably, the colonialists would have wanted to improve the comprehensibility of the Town by replacing the old order with the one they knew better, i.e., the order of western medieval cities, not only to enforce better control but also to improve health and sanitary conditions within the Town [22].

Karimi [11] compared the axial structure of some small English towns representing western medieval cities with that of some small Iranian cites representing traditional Islamic cities using Space Syntax techniques, and noted several similarities as well as differences between these two groups of cities. Some of the more important syntactic values reported by Karimi are provided in the Table 1 with the similar values for the three maps of Zanzibar used in this study.

It can be observed that with 837 the total number of axial line is the highest in the axial map of 1892. It then drops to 687 in the 1922 map before increasing to 830 in the present map, which is still less than the number we find in 1892 map. This is surprising in light of the fact that since the middle of the 19th century the town has been growing in geographical area and population size. Yet, the total number of axial line decreased significantly during the colonial period. This can probably be explained by the fact that in the Islamic phase, as noted above, streets of the town were generally more tortuous supporting the way of life of the communities within. However, after the British took control they straightened up many of these tortuous streets in order to improve the overall living conditions of the population by extending the effectiveness of routine health and sanitary inspections by colonialists, as well as to improve movement within the town for exercising power and control. As a result, a very high number of axial lines that were needed to cover the old Islamic town reduced significantly in the town controlled by the British.

The above observation is also supported by the fact that, in the 1892 map the mean connectivity value of axial lines is lower than it is in the 1922 map. Again, it is possible to explain this fact by invoking the need for privacy in Islamic societies and the need for exercising power and control by the British rulers. The logic of Islamic societies needed less connected streets to promote a 'fused' sense of space, and the logic of colonial rulers needed more connected streets to improve movement. This observation is further supported by Karimi [11], who reports that Islamic cities have lower mean connectivity value than the English medieval towns that probably had favored movement more than privacy.

The fact that the 1892 and 1922 maps of the town may represent two different types of social and economic system is also supported by their mean integration and $\mathrm{r}^{\wedge} 2$ values. Table 1 shows that the radius-n, radius-3, and radius-5 integration values of the town have increased from its early Islamic phase to its colonial phase. This is also true for the $\mathrm{r}^{\wedge} 2$ values representing intelligibility of these urban systems. According to these values, the 1922 map has much better intelligibility than the 1892 map regardless of how the local syntactic values are defined. These observations are consistent with those made by Karimi [11]. Karimi showed that integration was lower for Islamic cities than English medieval cities.

That the present-day map of the town has even higher mean connectivity and integration values than the colonial town can be explained by the tourist-dominated economy of this post-colonial town. In its earlier phases, the town had served both commercial and residential functions. Today, the old residential functions of the town are being replaced by commercial functions serving tourists, for which movement is of primary importance. This may also help explain why intelligibility of the present day map is somewhat inconsistent in relation to the 1922 map. For the present day map, intelligibility is worse at radius- 1 \& -3 but is better at radius-5 when compared with that of the 1922 map. In other words, the post-colonial town is becoming more globally oriented at the cost of its local level intelligibility. 


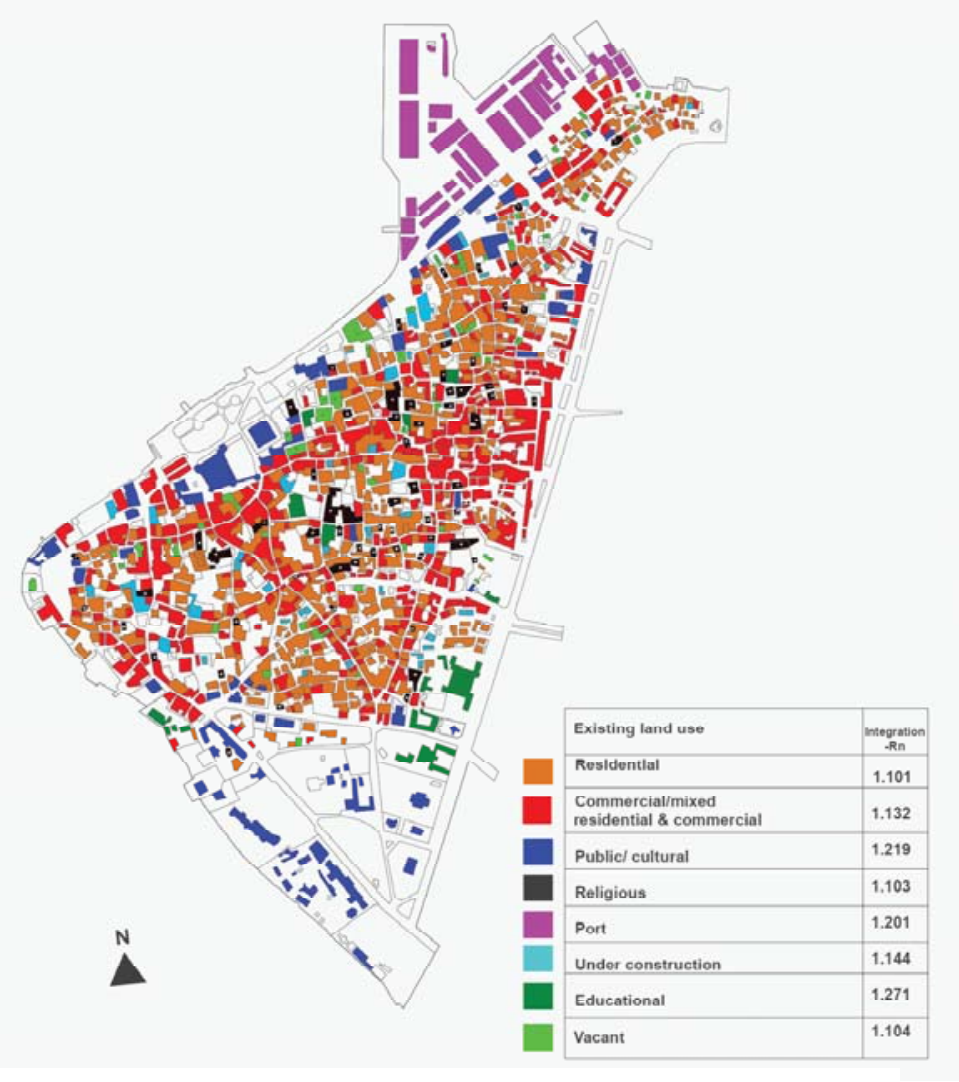

Figure 19: The mean integration values for different land uses in Zanzibar in the 1990s.

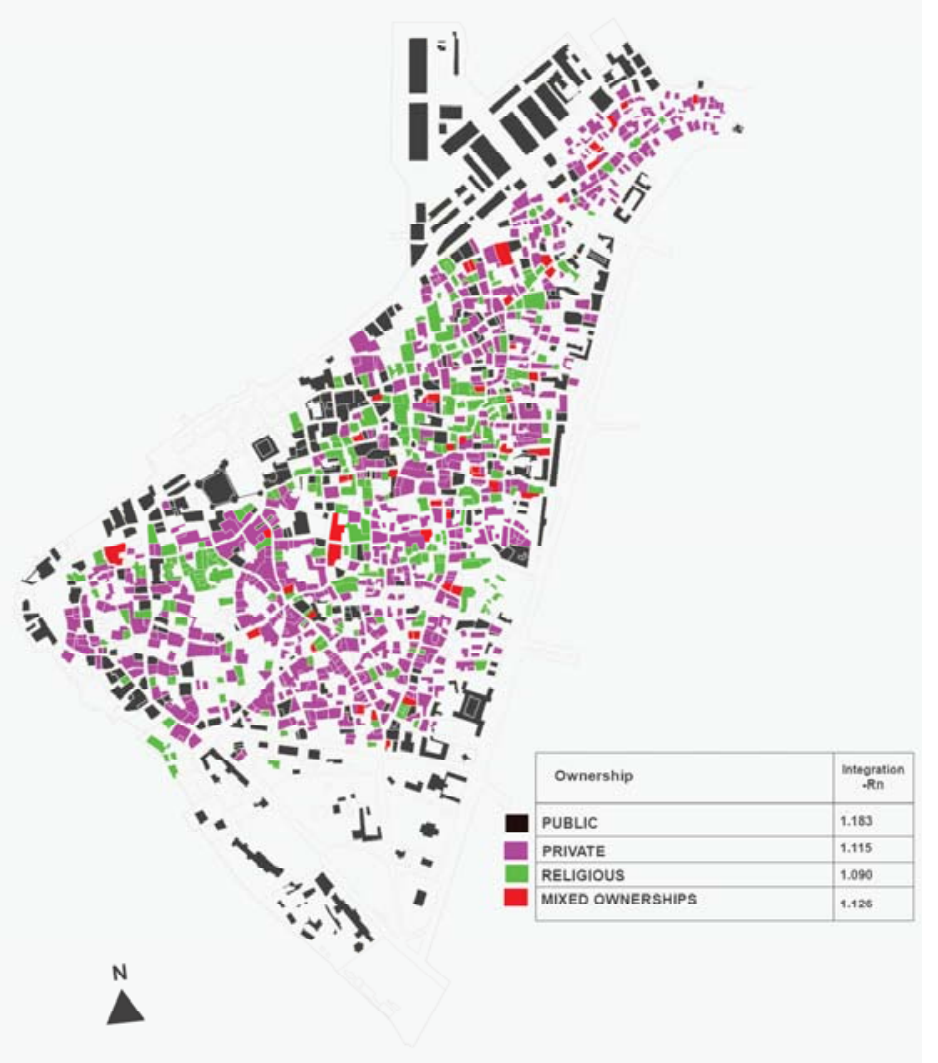

Figure 20: The mean integration values for areas based on ownership in Zanzibar in the 1990s.

\section{THE PRESENT: ANALYSIS OF FUNCTIONAL MORPHOLOGY OF THE TOWN}

The study of functional morphology aiming at understanding the relationship between structure and function in the Stone Town were based on the following maps, which were prepared by the Aga Khan Trust for Culture in the early 1990s and were published in Siravo [7]: 1) a land use map showing the location and distribution of building activities in the town (Figure 19); 2) a building ownership map showing private, public and religious ownership of buildings in the town (Figure 20); 3) a map showing the major building types in the town according to antecedents and original use(Figure 21); 4) a map showing many buildings and architectural and streetscape features which represent architectural, historical or cultural achievements, or which are significant examples of their types (Figure 22); and 5) a map showing new building and building alterations in the town(Figure 23).

Each of the above maps were overlaid on the axial map of the town in order to find out how the functions represented in the map were correlated with the distribution of integration values in the map (Figure 24). The mean integration value of the map at radius-n, which is 1.113 , was used here as the benchmark. If the mean integration value of a function is less than the mean integration value of the whole town, then it can be argued that the function is generally located in the segregated areas of the town. In contrast, if the mean integration value of a function is more than the mean integration value of the whole town, then it can be argued that the function is generally located in the more integrated part of the town.

The existing land use map (Figure 19) of the town shows that with the exception of residential, religious, and vacant areas of the town, all other areas have higher mean integration values than the mean of the town as a whole. These other areas include commercial functions, public/cultural functions, port functions, educational functions, and the areas under-construction. The fact that residential functions are located in the segregated areas of the town makes intuitive sense, because they need privacy. The fact that religious func- 


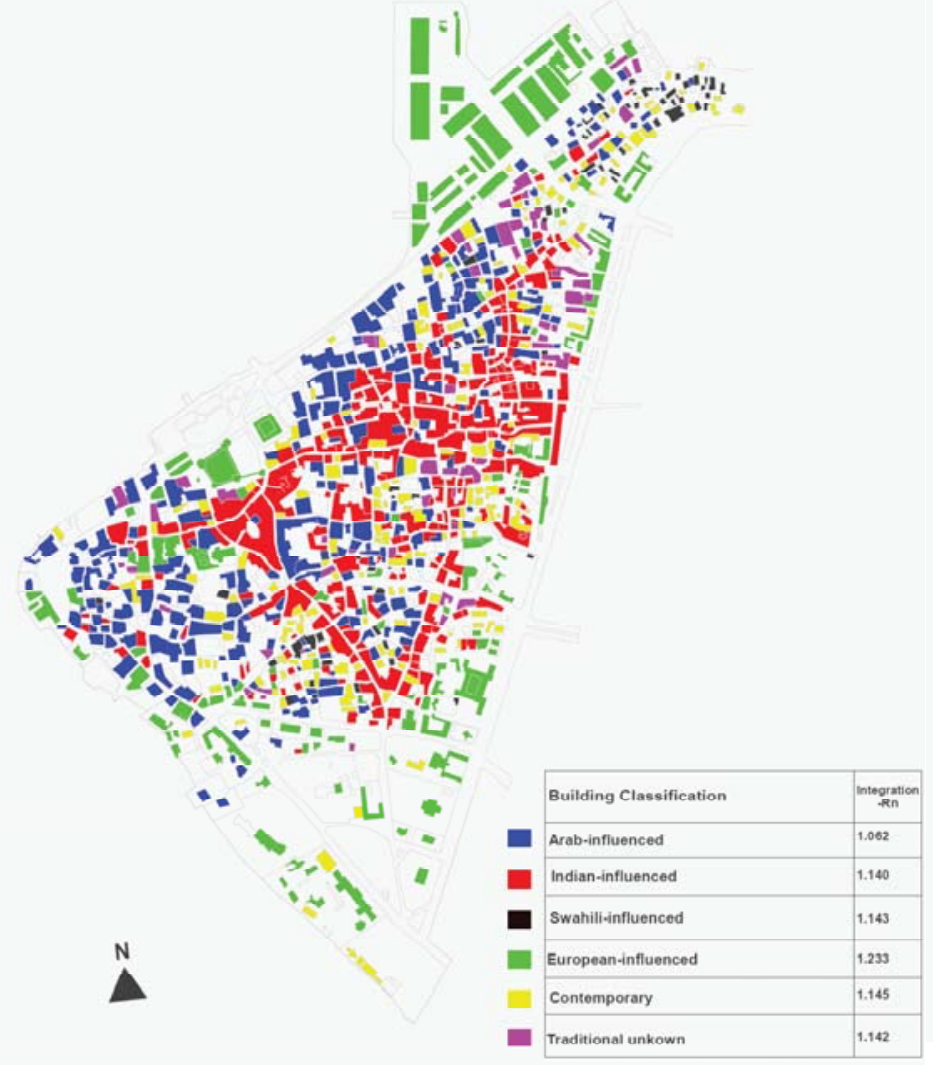

Figure 21: The mean integration values for buildings classified based on ethnic influences in Zanzibar in the 1990s.

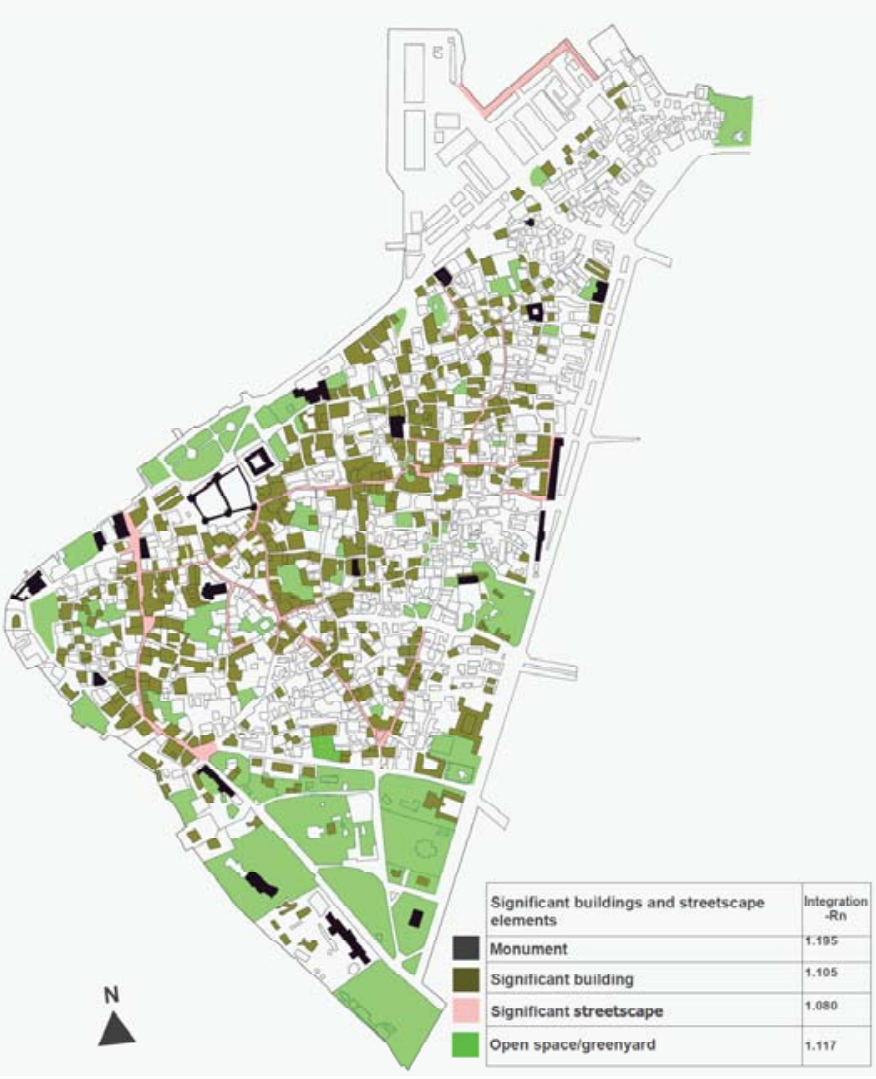

Figure 22: The mean integration values for significant buildings and streetscape elements in Zanzibar in the 1990s.

tions are located in the segregated areas can be explained in relation to residential functions. Historically, most religious buildings in the town were associated with families or communities that built them. As a result, most of them are to be found within residential areas. The fact that vacant areas have lower mean integration than the areas under construction also makes sense, because most of the new construction areas appear to be located in the established commercial area of the town. This is also supported by the fact that current land use policy does not encourage any new residential use in the town.

The existing ownership map (Figure 20) shows the areas under public and mixed ownership have higher mean integration values than the mean of the town as a whole. It can be observed here that if this map is overlaid on the axial maps of the present town most of the public buildings are located close to the integration core around the perimeter of the town (Figures 16, 17, \& 18). It can also be observed that most areas under mixed ownership are mostly commercial functions, which, as was observed before, have higher mean integration than the average mean of the town as whole. In contrast, most areas under private and religious ownership are in the inner parts of the town, as a result they generally have lower mean integration values that the areas under public and mixed ownership.

The existing building classification map (Figure 21) shows the Arab-influenced buildings to be located in the segregated areas of the town with lower mean integration values than the mean of the town as a whole, because a large number of Arab houses were built for residential functions only. Therefore, they were built in the private areas of the town. In contrast, the Hindu- and Swahili- influenced buildings are located in the more integrated parts of the town, because most Hindu and Swahili inhabitants of the town were engaged in commercial activities and ran their commerce from their houses. Therefore, they found it more profitable to build 


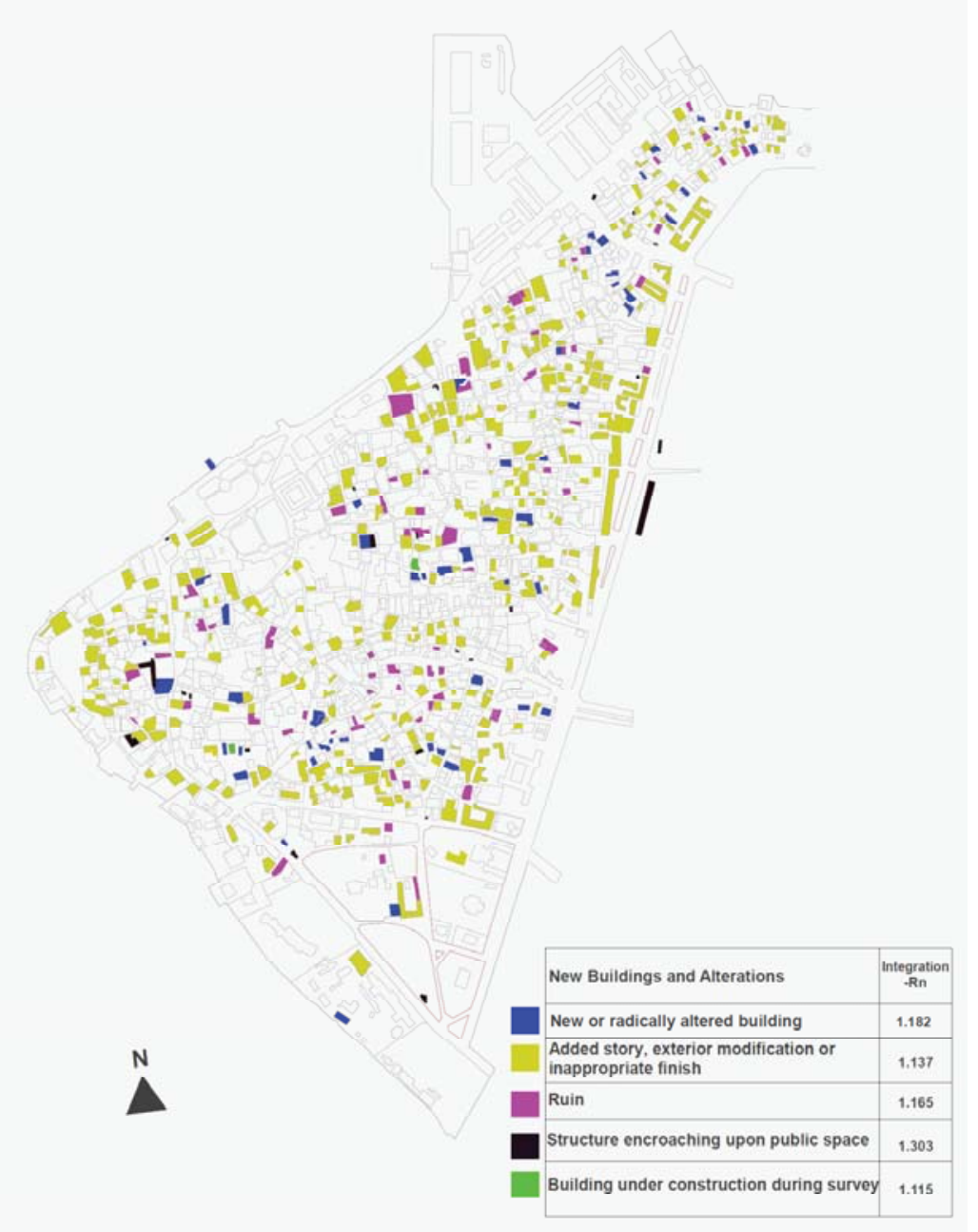

Figure 23: The mean integration values for new buildings and alterations in Zanzibar in the 1990s.

their buildings in more integrated parts of the town. The European-influenced buildings are located in the more integrated part of the town, because many of them now serve as public buildings that are located close to the integration core of the town. Since most of the contemporary buildings serve commercial functions, it is only natural that they would be located in the integrated parts of the town.

The map showing the significant building and streetscapes (Figure 22) has the monuments, which include most of the historic buildings of the town, in the more integrated areas of the town. Other significant buildings are located in rather segregated areas of the town, which is interesting but can be explained looking at the history of the town. A large number of these significant buildings were owned by the ruling Omani Arabs, who preferred to build their houses in the segregated part of the town for privacy reasons. Significant streetscapes, which are located in the inner parts of the town, are also relatively segregated because the inner parts of the town are generally more segregated than the parts of the periphery. In contrast, the public open spaces are more integrated because they located around the town as well as in the inner parts of the town. It can be recalled here that the open spaces created by the British are the larger ones on the southern and eastern sides of the town, and they are located on two very integrated streets in the southeastern part of the town.

Finally, the map showing new buildings and building alterations (Figure 23) has new or radically altered buildings on highly integrated axial lines. This makes sense because most new buildings are commercial buildings located on integrated streets to become commercially viable. Buildings that have exterior additions or alterations and buildings that are encroaching upon public spaces are also located on integrated lines, because most of these changes are being in response to the commercial needs generated by tourism. The fact that ruins are located in areas with more integration than the mean value of the town may appear a bit puzzling, but it is not. 


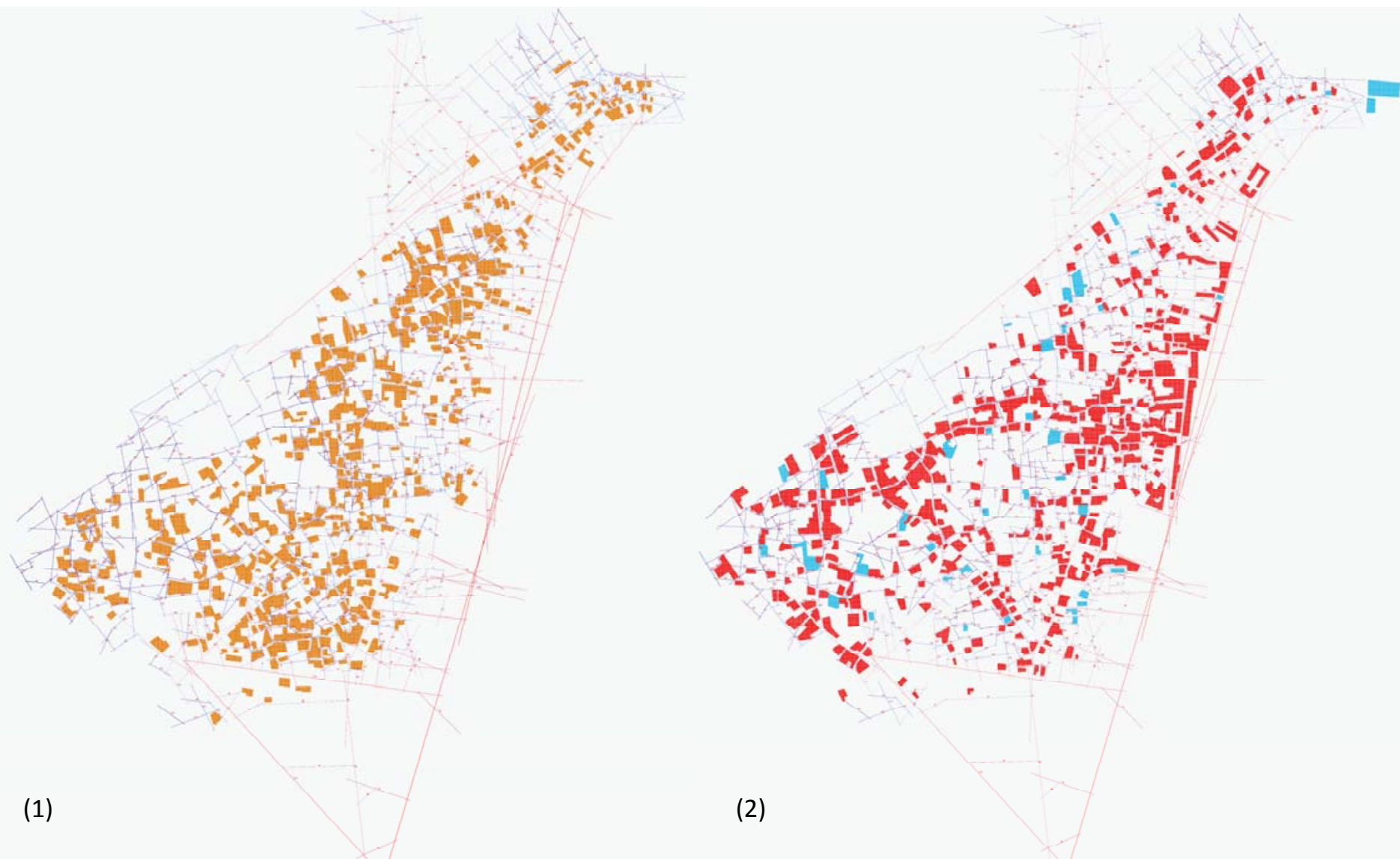

Figure 24: These diagrams show how the mean integration values for different functions in the Stone Town were computed. In stage 1, different functions were isolated on separate layers of a drawing. Each of these layers representing a function was then overlaid on the axial map to identify all the lines that had the function located on them. For example, Diagram 1 shows the axial map with residential buildings only, while Diagram 2 shows the axial map with commercial and mixed-use buildings only. The mean integration value of a function was computed by taking the mean of the integration values for all the axial lines that had the function located on them.

Many ruinous buildings are old historic buildings, hence are also located on important well-connected streets.

\section{DISCUSSION \& CONCLUSION}

The significance of the study reported in this paper is discussed, first, in relation to the Stone Town itself. Here, the focus is on the three hypotheses proposed earlier in the paper. Then, it is discussed in relation to the methodology of the paper emphasizing the fact that it provides an effective way to conduct historical research using Space Syntax. Finally, the significance of the study is discussed in relation to the socio-spatial and spatio-temporal processes, emphasizing the relationship between design and politics, of traditional cities of Africa, India, and other places that went through similar historical experiences, as did the Stone Town of Zanzibar.

Concerning the three hypotheses of the study

The syntactic analysis of historical and functional morphology of the Stone Town of Zanzibar has validated all three hypotheses stated earlier in the paper. Concerning the first hypothesis, it was observed that the British did not modify the existing Islamic fabric of the town in any significant way. Yet they were able to change the morphological structure of the town through changes in the southern and eastern edges of the town only. Earlier, the syntactic center of the town was towards the western sea side of the town. Because of the British spatial interventions, the center moved to the eastern side of the town, which until that time was the least desirable area of 
the town. As a result, the British were able to change the social and economic dynamics of the town in a rather significant way. Interestingly enough, the structure of the town continued its morphological evolution until today through many small-scale changes. Today, the syntactic center of the town has moved around the perimeter of the town. This change, in a way, may support the recent attempts at conserving the inner core of the town by guiding traffic flow around its perimeter.

Concerning the second hypothesis, it was observed that the syntactic structure of the axial map of 1892, characterized by higher density of axial lines and lower mean connectivity and integration values, left most of the inner part of the town rather segregated. This characterization supported privacy in the residential quarters of a predominantly Muslim society. In contrast, the syntactic structure of the town in 1922 under the British assumed a very different character with lower density of axial lines and higher mean connectivity and integration values. This signaled a shift in the urban culture of the town from a predominantly Islamic one to an economic one that emphasized movement while recognizing the existing urban culture. This shift in the structure of the town was further substantiated through a comparison with traditional Islamic cities and western medieval cities. The shift, however, becomes more complete in the town at present time where the previously segregated residential quarters are being increasing integrated within the axial structure of the town further supporting an economy based on movement.

Concerning the third hypotheses, the analysis of functional morphology of the town at present time revealed a remarkable degree of structural dependency of functions. Whether it was land use, building ownership, building typology according to antecedents and original use, significant buildings and streetscape features, or new buildings and recent alterations in the town - the distribution pattern of every type of function showed some correlation with syntactic integration. One fact that might have contributed to structural dependency of functions in the town was its process of growth. As the town grew around its edges keeping the inner areas relatively intact, the syntactic core of the city always remained on the edge/s of the town. Therefore, all new functions developed along the edges in order to take advantage of syntactic centrality, and many old functions within the inner areas of the town were able to retain their primitive characters.

Based on the axial map analysis, this study thus revealed a dialectical relationship between historical and functional morphology of the Stone Town of Zanzibar, which helped explain significant aspects of its process of growth and evolution. Among the things identified in the study were the stages of significant structural transformations in the evolutionary process of the city. The study identified how, through small-scale changes, the structure of this town changed significantly more than one time. It also identified a ubiquitous structural dependency of functions, which helped explain why the town was able to preserve its identity and continuity. It was explained that because of its unique process of growth and change, the town repeatedly externalized its syntactic centers at its edges. These externalized syntactic centers then attracted new functions on and around the edges sparing the inner areas of the town from indiscriminate changes.

In summary, this study showed how a city may undergo significant structural changes even when its physical fabric show continuity and consistency; and how, despite its structural changes, the city may still preserve many of its early characters and functions. In future studies, it will be necessary to show if a city may grow without any significant structural changes to its morphology, or if structural change is an inevitable consequence of its physical growth. It will also be necessary to show if a city may experience significant changes in its physical fabric without showing significant structural transformations.

\section{Concerning historical research and Space Syntax methodology}

Concerning historical research involving urban form, it is necessary to acknowledge the temporality of space and of society, without which no understanding of the relationship between urban form and society can be complete. In other words, to uncover historical reality multiple layers of description that Geertz called "thick description” [23] are needed. Within Space Syntax, it is possible to imagine several ways to achieve such a multiplicity of description. For example, an analysis that uses both axial description emphasizing linearity of move- 
ment and convex description emphasizing the static nature of social interaction may provide a better account of historical reality than any one of the Space Syntax descriptions. Griffiths [24] found such a multiplicity useful to explain how the cutlery industry in early industrial Sheffield sustained itself over a rapidly extending urban area.

Another way to obtain historical richness within Space Syntax is to use different modalities of distance - topological, angular, and metric - simultaneously in the description of cities. For example, in this paper the technique of axial map analysis of Space Syntax has proven to be a powerful tool in revealing the dialectics of historical and functional morphology in the changing processes of the city. More recently, however, Space Syntax researchers have also used angular distance or the techniques of angular segment analysis (ASA) [25, 26] in studies on social and economic activities of cities with some success. In short, ASA breaks the lines of an axial map into segments at their intersections, and then finds the sum of the angles turned from the starting segment to any other segment within the map. This angular sum is then treated as the 'cost' on pays as one takes a trip from one segment of the representation to another. It is generally assumed that the higher the angular sum the more one pays for a trip. Turner [27] as well as Hillier and Iida [28] show that ASA measures of a linear representation are excellent predictors of movement patterns in urban environments. Vaughan [29] uses the technique to describe the relationship between poverty and space in the 19th century London, and Griffiths et al. [30] to describe the relationship between suburban built form and socio-economic activity in Greater London, thus indicating some usefulness of this technique for the kind of morphological analysis presented in this paper.

Yet another way to obtain historical richness within Space Syntax is to use its descriptive techniques at multiple scales. Instead of a binary pairing of 'local' defined at a radius less than the maximum radius of a spatial system and 'global' always defined at the maximum radius of the system, a pairing that was used in this study, it is possible to imagine a more historically contingent grouping of descriptions defined at several scales to explain human activities at a greater depth.

Of course, the most obvious way to obtain historical richness within Space Syntax is the one that has been used in this paper. It involves analyzing multiple morphological frames of a city using any one or more techniques of space syntax. In this case, however, the selection of the morphological frames is important; and the selection needs to be historically contingent for a meaningful understanding of the relationship between urban form and human activities. For example, cities with fewer historical changes may require fewer morphological frames than those with more frequent historical changes.

In spite of the fact that this paper failed to report a richer comparative morphological analysis of the Stone Town of Zanzibar using all different analytic techniques of Space Syntax, the methodological contribution of this paper to historical research on urban form is quite clear. Urban historical research using Space Syntax has a long distinguished record, but with the exception of a few recent studies most early studies have taken a very synchronic view of cities and urban structures for a good reason [31]. Since the overriding task of Space Syntax researchers in conducting most of the early urban historical studies was to articulate a formal morphological theory of cities, they were somewhat forced to undermine the spatio-temporal nature of cities. Thus, Griffiths [31] notes that if Space Syntax wants to engage more directly with history of cities they should now refocus of a theory of time-space description of cities instead of a theory of spatial description. The methodology offered in this paper has done precisely that.

\section{Concerning the relationship between design and the politics of power}

Finally, the issue that needs attention here is the relevance and contribution of this study to our understanding of traditional cities of Africa, India, and other places that went through similar historical experiences, as did the Stone Town of Zanzibar. As noted earlier, for the first two hundred years of its history the Stone Town had evolved under a traditional maritime economy dominated by the Arab-Islamic worldview. This was then followed by about 75 years of British colonial rule, with an ever-diminishing role of the Arab ruling class in an international maritime economy of the Stone Town. Finally, after the Revolution of 1964 the Stone Town started its postcolonial phase with a market economy based on tourism. Therefore, one must ask, "How does the study 
of historical and functional morphology of the Stone Town, as revealed through Space Syntax, inform our understanding of the processes of spatialization in other colonial cities around the world?”

The above question is important for many reasons. First, finding an answer to the question may help us understand the importance of the study within its global context. Second, since the structure of space, as described by Space Syntax, is inaccessible to conventional language, most urban historical studies of colonial cities often depend on representational spaces to describe the politics of power [e.g., 32-34]. Thus, the role of spatial structure in the socio-spatial and socio-temporal processes of colonial cities remains unknown. Third, most of the previous studies focus on radical spatial interventions of Colonialism aimed at social engineering based on legitimacy and control [e.g., 13, 19, 35]. Often conceived in the form of monumental built forms, neighborhood planning, and model housing schemes that were unknown to local cultures, these spatial interventions were the tools of the 'geographical imagination' of British colonialism and imperialism, to use Said's phrase [36, 37].

However, one is often surprised with the fact that the colonial spatial interventions within the Stone Town of Zanzibar generally appear modest and less confrontational when compared with the other interventions often discussed in the literature. Examples of these spatial interventions already exist in Ng'ambo, which is the other side of the Stone Town [e.g., 13, 35]. Does this mean that the British were more reconciliatory in their approach within the Stone Town than they were in the other parts of the Stone Town? Could their social and political agendas in the Stone Town be different from that in the periphery of the Stone Town? This may not necessarily be the case. What will be argued below is that the social and political agendas of the British colonial rulers remained unchanged despite the fact that they used different kinds of spatial interventions in different parts of the Stone Town, and that we are able to make such an assessment because the structure of space, as described by Space Syntax, can often tell a story that the naked eye fails to see.

Timothy Mitchell's concept of 'enframing' is used here to understand the implications of British interventions in the Stone Town of Zanzibar [38]. The concept includes the three following spatial strategies: 1) the making of a segmented plan to replace the native urban "orders without frameworks"; 2) the creation of distinctions between "inside and outside” at various spatial scales”; and 3) the strategy of objectifying space via provision of points of observation and places of surveillance. According to Mitchell [38], these spatial strategies made colonial urbanism different from European and American urban projects.

In her study of 'Native Locations' in South Africa, Robinson [39] shows that the first of these strategies involved altering African “orders without frameworks” to an order reducible to a segmented plan where racial segregation was inherent. However, it also reinforced the colonial power by extending the effectiveness of routine health and sanitary inspections by colonialists. The second strategy involved creating a fixed distinction between inside and outside in domestic architecture, thereby codifying neighborhood, family, and gender relations in a manner distinct from African systems of domestic order. This fixity between inside and out extended the effects of the first strategy down to various microscales. The third strategy often involved providing well-surveilled central spaces of observation. On the one hand, these spaces served as reminders of the might of colonial powers to the general population. On the other hand, they allowed the natives, who brought with them a communal, "fused" concept of space, to observe and survey the colonial city and urban projects from a distance; thereby helped normalize the city in their eyes.

British Colonialism's three themes of enframing though not always clearly visible in the physical fabric of the Stone Town, they become quite clear in the spatial structure of the Stone Town as represented by Space Syntax. Of course, the colonial spatial interventions in the Stone Town did not transform the Stone Town from an "order without frameworks" into a well-defined segmented plan with easily identifiable zones, but they did change the structural orientation of the Stone Town quite radically as was noted in this study. As a result, the colonialists were able to achieve many of the goals of a segmented plan without really implementing one in the Stone Town. For example, they were able to establish a 'new front' on the east side of the Stone Town that was syntactically more privileged, undermining the importance of the traditional economy and power structure of 
the Stone Town that were founded on the west side of the Stone Town. More visible, however, was the notion of racial segregation in the colonialists' spatial interventions. For example, they selected Vuga, which was an almost unbuilt area in the southeast of the Stone Town, for their own residential enclave. To the natives, thus, the enclave appeared physically separated from the rest of the Stone Town promoting the colonialists' notion of racial segregation. Interestingly enough, since several changes in the street network also brought the British enclave syntactically closer to the Stone Town than the western part of the Stone Town where the traditional seat of power was, the colonialists were now able to control the everyday function of the Stone Town more efficiently. Additionally, the syntactic and metric proximity of the British enclave to Ng'ambo also allowed the colonialists to extend their control to this area, which until now was left to grow on its own.

This study presented no direct evidence in support of the second spatial strategy of British colonialism that involved creating a fixed distinction between inside and outside in the domestic architecture of the Stone Town. However, it is rather clear from the syntactic analysis that the colonialists' spatial interventions did result in some significant changes within the neighborhoods of the Stone Town. Most importantly, these interventions helped increase the overall interconnectedness and intelligibility of these neighborhoods. The old intimate and private neighborhoods of the Stone Town, where the structure of space allowed inside and outside, private and public, to fuse easily into one another in everyday life, were now reorganized in a way so that a more connected exterior with a more vibrant public life did not allow the interior private life to come in its contact easily. As a result, in an indirect way the colonialists helped create conditions for a fixed distinction between inside and outside through space in the Stone Town's neighborhoods. Whether this spatial strategy played itself out according to Mitchell's concept of enframing requires further validation through historical research.

In contrast to most previous studies on colonial cities that used large and/or monumental spaces as evidence for the third spatial strategy of British colonialism involving how space was objectified via provision of points of observation and places of surveillance in the city, this study helped extend this spatial strategy down to microscales of the Stone Town. Of course, the British created quite a few large public open spaces in the Stone Town. Mnazi Mmoja and Jamhuri Gradens are probably the best examples of the colonial public open spaces in the Stone Town (Figures 2 \& 3). Created on the land reclaimed from the creek that separated the Stone Town from Ng'ambo, these gardens served not only as a reminder of colonial powers to the general population, but also allowed the natives to observe and survey from a distance the colonial enclave in Vuga and other important colonial buildings along the Creek Road. As a result, as suggested by Mitchell's concept of enframing, these spaces helped normalize the colonial presence in the Stone Town. However, according to this study the strategy of using urban spaces as points of observation and places of surveillance was not limited only to a few large spaces of the Stone Town. The British had widened many narrow streets, and straightened many others that were meandering in the Stone Town. As a result, the interior of the Stone Town became more accessible; thus making surveillance and control more pervasive. In effect, the colonialists changed the whole spatial structure of the Stone Town to make it 'readable like a book', to use Mitchell's phrase [38].

No doubt, the Space Syntax analysis of functional and historical morphology of the Stone Town of Zanzibar helped validate Mitchell's concept of enframing yet another time; but this time in ways that were not known before. Most important, of course, is the fact that the colonialists' spatial strategies were not always applied via large scale urban forms and spaces. They were also applied via small scale projects that might have involved simply straightening, widening, and/or reconnecting streets. Though the effects of these small changes are not often critically examined, the collective effects of these changes on the city sometimes may be as impactful as the large scale projects, as this study indicated. The study also indicated that sometimes the colonialists were more subtle in their enframing than what the literature has acknowledged so far.

\section{REFERENCES}

1. L. Martin, 'The grid as generator', in L. Martin, \& L. March, Eds., Urban space and structures (Cambridge, Cambridge university press, 1972). 
2. T. Schumacher, 'Buildings and streets: notes on configuration and use', in S. Anderson. Ed., On Streets (Cambridge, MA, MIT Press, 1986), pp. 133-149.

3. A. Siksna,. The effects of block size and form in North American and Australian city centers, Urban Morphology, 1(1997), pp. 19-33.

4. M.Southworth, P. Owens, 'The evolving metropolis: studies of community, neighborhood, and street form at the urban edge', APA Journal, 59:3(1993), pp. 271-287.

5. B.Hillier, J. Hanson, The social logic of space (Cambridge, Cambridge University Press, 1984).

6. Hillier, B. Space is the machine: a configurational theory of architecture (Cambridge, Cambridge University Press, 1996)

7. F. Siravo, Zanzibar: A plan for the Historic Stone Town (Geneva, The Aga Khan Trust for Culture, 1996).

8. A. Sheriff. Slaves, spices, and ivory in Zanzibar (London, James Currey, 1987).

9. A. Sheriff, Ed., The History and conservation of Zanzibar Stone Town (London, James Currey, 1992).

10. A. Sheriff, 'Mosques, merchants, and landowners,' in A. Sheriff, Ed., The History and conservation of Zanzibar Stone Town (London, James Currey, 1992), pp. 46-66.

11. K.Karimi, 'The spatial logic of organic cities in Iran and the United Kingdom,' in Proceedings of the First International Space Syntax Symposium, Vol. 1, (London, University College London, 1997), pp. 5.1-5.18.

12. E. Dutton, Kenya mountain (London, Jonathan Cape, 1929).

13. G. Myers, 'Designing power: forms and purposes of colonial model neighborhoods in British Africa,' Habitat International, 27 (2003), pp. 193-204.

14. F. Cooper, On the African Waterfront: Urban Disorder and the Transformation of Work in Colonial Mombasa (New Haven, Yale University Press, 1987).

15. R. Sack, Conceptions of Space in Social Thought (Minneapolis, University of Minnesota Press, 1980).

16. L. Alexander, 'European planning ideology in Tanzania', Habitat International, 7:1/2 (1983), pp. 17-36.

17. J. de V. Allen, 'The Swahili house: Cultural and ritual concepts underlying its plan and structure', Art and

Archeology Research Papers, 1: Special Issue (1979), pp. 1-32.

18. L. Donley-Reid, 'House power: Swahili space and symbolic markers,' in I. Hodder (Ed.), Symbolic and structural archeology (Cambridge, Cambridge University Press, 1982), pp. 63-73.

19. G. Myers, 'Colonial and Postcolonial Modernities in Two African Cities', Canadian Journal of African Studies / Revue Canadienne des Études Africaines, 37:2/3 (2003), pp. 328-357.

20. S. A. Nilsson, M. Glaumann, P. Krabbe, K. Sundstrom, P. Wisth, 'Tanzania: Zanzibar's present conditions and future plans: House building and planning in developing countries,' Research Pamphlet, University of Lund Department of Architecture, Lund, Sweden, 1969.

21. R. Biles, Transcript of interview with former Zanzibar chief of police R.H.V. Biles, interviewed by J.J. Tawney, December 11, 1971 (Oxford, Rhodes House Library, 1971).

22. B. Yeoh, Contesting space: Power relations and the urban built environment in colonial Singapore (Oxford, Oxford University Press, 1996).

23. C. Geertz, The Interpretation of Cultures (Basic Books, New York, 1973).

24. S. Griffiths, 'Persistence and Change in the Spatio-temporal Description of Sheffield Parish 1770-1910', in

D. Koch, L. Marcus, J. Steen (Eds.), Proceedings of the 7th International Space Syntax Symposium, Stockholm, KTH Royal Institute of Technology, 2009, pp. 37.1-37.15.

25. R. Conroy Dalton, Spatial navigation in immersive virtual environments, Unpublished doctoral dissertation, University College London, London, 2001.

26. A. Turner, 'Angular analysis', in J. Peponis, J. Wineman, S. Bafna (Eds.), Proceedings of the 3rd International Space Syntax Symposium, Atlanta, Georgia Tech, 2001, pp. 30.1-30.11.

27. A. Turner, 'From axial to road-centre lines: a new representation for space syntax and a new model of route choice for transport network analysis,' Environment and Planning B: Planning and Design, 34:3 (2007), pp. 539 -555 . 
28. B. Hillier, S. Iida, 'Network effects and psychological effects: A theory of urban movement', in Proceedings of the 5th International Symposium on Space Syntax, Vol. 1, Delft, Netherlands, TU Delft, 2005, pp. 553-564. 29.L. Vaughan, 'The spatial form of poverty in Charles Booth’s London,' Progress in Planning, 67 (2007), pp. 205-294.

30. S. Griffiths, C. E. Jones, L. Vaughan, M. Haklay, 'The persistence of suburban centres in Greater London: combining Conzenian and space syntax approaches,' Urban Morphology, 14:2 (2010), pp. 85 - 99.

31. S. Griffiths, 'Temporality in Hillier and Hanson's theory of spatial description: some implications of historical research for Space Syntax,' The Journal of Space Syntax, 2:1 (2011), pp. 73-96.

32. Z. Celik, Urban forms and colonial confrontations: Algiers under French Rule (Berkeley and Los Angeles, CA, University of California Press, 1997).

33. C. Rakodi, 'Colonial urban planning in northern Rhodesia and its legacy,' Third World Planning Review, 8 (1986), pp. 193-218.

34. G. Wright, The politics of design in French colonial urbanism (Chicago, IL, University of Chicago Press, 1991).

35. G. Myers, ‘A stupendous hammer: colonial and post-colonial reconstruction of Zanzibar’s Other Side', Urban Studies, 32:8(1995), pp. 1436-49.

36. E. Said, Culture and imperialism (New York, Harper and Row, 1993).

37. E. Said, 'Secular interpretation, the geographical element, and the methodology of imperialism', in G.

Prakash (Ed.), After colonialism (Princeton, NJ, Princeton University Press, 1995), pp. 21-39.

38. T. Mitchell, Colonizing Egypt (Cambridge, Cambridge University Press, 1988).

39. J. Robinson, “A Perfect System of Control'? State Power and 'Native Locations' in South Africa', Environment and Planning D: Society and Space, 8:2 (1990), pp. 135-62. 